\title{
Influência do agregado reciclado na durabilidade do concreto armado frente a corrosão de armadura desencadeada por carbonatação acelerada
}

\section{Influence os recycled aggregate on the durability of reinforcemend concrete in front of the corrosion of reinforcement released by accelerated carbonation}

\author{
Carlos F. G. Nascimento ${ }^{1 *}$, Thaís M. Silva ${ }^{2}$, Igor A. R. Teixeira ${ }^{3}$, Flaviana G. A. Silva ${ }^{3}$, Daniely \\ C. M. Neves, Paula G. V. Pedrosa ${ }^{3}$, Débora C. P. Valões ${ }^{3}$, Eliana C. B. Monteiro ${ }^{3,4}$
}

\begin{abstract}
RESUMO
A construção civil gera impactos ambientais devido a produção dos resíduos de construção e demolição (RCD). O principal objetivo desse artigo é estudar a durabilidade dos concretos produzidos com diferentes percentuais de agregado reciclado em sua matriz analisando seus comportamentos. Foram confeccionados corpos-de-prova (CP's) prismáticos com dimensões $(10 \mathrm{~cm} \mathrm{x} 10 \mathrm{~cm}$ x $6 \mathrm{~cm})$ contendo barras de aço com diâmetro $\varnothing$ de $6 \mathrm{~mm}$ e, a partir disso, foram moldadas 4 famílias: sem (RCC) - referência, com 15\%, 25\% e $50 \%$ de substituição parcial do agregado natural pelo (RCC). Os (CP's) foram utilizados para analisar o comportamento dos traços confeccionados através do ensaio de potencial de corrosão, após a exposição acelerada de $\left(\mathrm{CO}_{2}\right)$ (dióxido de carbono) presente na câmara de carbonatação. Para os (CP's) de referência e com 15\% de (RCC) tiveram, em 30 dias, potencial de corrosão denominado na zona de incerteza com $321 \mathrm{mV}$ e $-335 \mathrm{mV}$, respectivamente. Para os (CP's) com 25\% e 50\% de RCC, os comportamentos do potencial de corrosão variaram entre $-352 \mathrm{mV}$ e $-370 \mathrm{mV}$ podendo constatar que os traços com $50 \%$ de (RCC) incidem a corrosão das armaduras e, sobretudo, afetam a durabilidade frente à contaminação de agentes agressivos.
\end{abstract}

Palavras-chave: Agregado reciclado; Corrosão de armaduras; Durabilidade, Sustentabilidade

\section{ABSTRACT}

Civil construction generates environmental impacts due to the production of construction and demolition waste $(\mathrm{CCW})$. Thus, the main objective of this paper is to study the durability of concrete produced with different percentages of recycled aggregate in its matrix analyzing their behavior. The materials used to make the specimens were characterized as to their granulometry. Prismatic specimens (TS's) with dimensions $(10 \mathrm{~cm} \times 10 \mathrm{~cm}$ x $6 \mathrm{~cm}$ ) containing steel bars with diameter $\varnothing$ of $6 \mathrm{~mm}$ were made and, from that, 4 families were molded: without $(\mathrm{CCW})$ - reference, with $15 \%, 25 \%$ and $50 \%$ partial replacement of natural aggregate by $(\mathrm{CCW})$. The (TS's) were used to analyze the behavior of the traces made through the corrosion potential test, after the accelerated exposure of $\left(\mathrm{CO}_{2}\right)$ (carbon dioxide) present in the carbonation chamber. For the (TS's) of reference and with $15 \%$ of (CCW) had, in 30 days, a corrosion potential named in the uncertainty zone with $-321 \mathrm{mV}$ and $-335 \mathrm{mV}$, respectively. For the (TS's) with $25 \%$ and $50 \%$ of $(\mathrm{CCW})$, the behaviors of the corrosion potential varied between $-352 \mathrm{mV}$ and $-370 \mathrm{mV}$ and it can be seen

\footnotetext{
${ }^{1}$ Universidade Federal de Pernambuco, Cid. Univ, Recife, Brasil *E-mail: carlos.fgnascimento@ufpe.br

${ }^{2}$ Universidade Federal de Santa Catarina, Trindade, Florianópolis, Brasil

${ }^{3}$ Universidade de Pernambuco, Madalena, Recife, Brasil

${ }^{4}$ Universidade Católica de Pernambuco, Boa Vista, Recife, Brasil
} 
that the traces with $50 \%$ of $(\mathrm{CCW})$ affect the corrosion of the armatures and, above all, affect the durability in the face of the contamination of aggressive agents.

Keywords: Recycled aggregate; Corrosion of reinforcement; Durability; Sustainability

\section{INTRODUÇÃO}

A indústria da construção civil, mesmo em tempos de crise é um dos setores que mais cresce, gerando alguns benefícios como empregos e aumento significativo do PIB do país, no entanto é responsável por um grande volume de resíduos gerados no meio ambiente, produção de gases como $\left(\mathrm{CO}_{2}\right)$ oriundos no sistema metodológico dos materiais cimentícios e pela perca de materiais naturais (MARTÍNEZ-MOLINA et al., 2015). Estudos realizados na década de 90 por Zordan (1997), evidencia a utilização desses materiais, mas explica que a perca nos processos construtivos está ligada a falta de mão de obra e falta de técnicas para minimizar esses desgastes.

A composição e a quantidade de RCC estão caracterizadas nas fontes geradoras desses rejeitos em fase de construções, reformas e demolições (COSTA; RIBEIRO, 2020; SOUSA et al., 2021). O Resíduo de Construção Civil é classificado conforme a resolução $n^{\circ} 307$ do CONAMA BRASIL (2002) em quatro classes distintas, mas esse estudo referem-se a classe A, pois são aos resíduos reutilizáveis ou recicláveis como agregados provenientes de demolição e construção de obras civis. Os RCC's gerados no Brasil, referente a classe A, giram em torno de $90 \%$ em massa, abrangendo concreto e argamassa, rochas naturais e material cerâmico.

Com relação ao percentual de RCC “Classe” A, alguns estudos reportam valores na faixa de $88 \%$ a $96 \%$ sendo $93 \%$ a média desses valores (MANFRINATO; ESGUÍCERO; MARTINS, 2008). Algumas pesquisas informam que o desempenho físico-mecânico do concreto composto de materiais reciclados em sua matriz garante suas propriedades (AZEVEDO et al., 2020; BARRETO et al., 2021). Além disso, durabilidade consiste na capacidade de as estruturas resistirem às influências ambientais previstas e definidas em conjunto de acordo com o projeto estrutural regulamentado pela NBR 6118 (ABNT, 2014).

A vida útil, a segurança, a confiabilidade e o risco dos sistemas de infraestrutura tornaram-se questões emergentes nos últimos anos devido às catástrofes naturais e 
humanas, questões de sustentabilidade e ao aquecimento global (FELIX et al., 2018). Nota-se que essa definição incorpora o conceito de desempenho, elaborado na década de 80 pela ISO 6241 (ABNT, 1984) e que apenas recentemente foi adotado na normalização brasileira pela NBR 15575 (ABNT, 2013). A manutenção estrutural é necessária quando realizada periodicamente, pois problemas estruturais devido as manifestações patológicas podem surgir principalmente quando uma estrutura de concreto armado está sendo afetada por agentes agressivos como carbonatação e íons cloretos que incide a corrosão de armaduras e, consequentemente, o tempo de vida útil é diminuído afetando o desempenho da edificação (ELLINGWOOD; FRANGOPOL, 2016).

O processo de corrosão divide-se em duas fases, iniciação e propagação. A fase de iniciação dar-se pelo processo de difusão de $\left(\mathrm{CO}_{2}\right)$, onde o gás carbônico penetra na matriz porosa do concreto reagindo com os hidróxidos de cálcio $\mathrm{Ca}(\mathrm{OH})_{2}$ presente na pasta de cimento, levando a formação do carbonato de cálcio $\mathrm{Ca}(\mathrm{CO})_{3}$ (Figura 1) conforme descrito por Köliö et al., (2017). A propagação é definida através da taxa de corrosão quando relacionada a disponibilidade de oxigênio, a umidade relativa, bem como a resistência superficial do concreto responsável pela redução das fissuras ocasionadas pelas movimentações e tensões microestruturais. O processo de corrosão das armaduras apresenta-se como a manifestação patológica com o maior índice de ocorrência em estruturas de concreto armado (ANDRADE; POSSAN; DAL MOLIN, 2017).

Figura 1 - Avanço da frente de carbonatação vs. redução do pH no concreto.

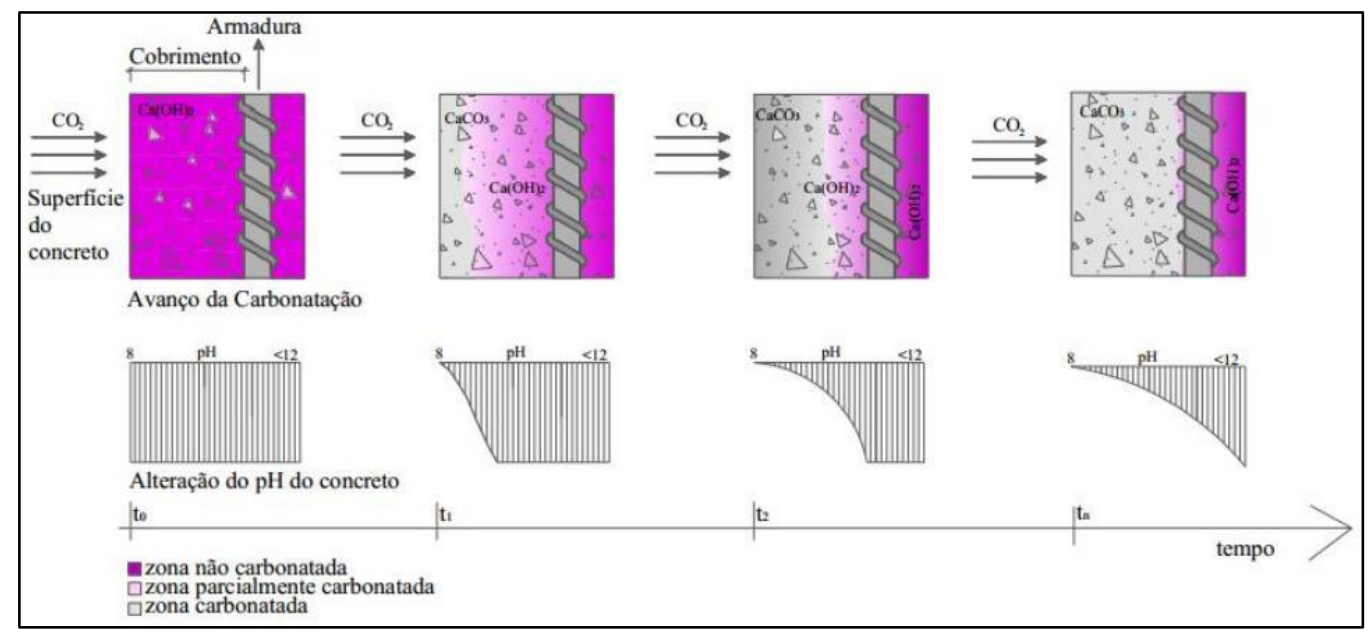

Fonte: Possan, (2010).

Assim, o objetivo principal desta pesquisa é desenvolver novas metodologias para a destinação dos resíduos gerados nas obras de construção e demolição que, muitas vezes, 
são descartados em locais inadequados, além de estudar experimentalmente o comportamento do mesmo na matriz do concreto. Em suma, então, conscientizar e determinar valores ambientais para mitigar os impactos ambientais é extremamente importante, pois a utilização dos materiais reciclados na construção civil minimiza o acúmulo de resíduos gerados nas obras e diminui a quantidade de emissões contaminantes ao meio ambiente.

\section{MATERIAIS E MÉTODOS}

Os materiais estudados nesta pesquisa e os ensaios de laboratório realizados estão apresentados a seguir focando na caracterização e preparação das amostras, confecção dos corpos-de-prova, condições de ensaio e caracterização físico-química. Os ensaios foram realizados no Laboratório de Estruturas e Materiais de Construção Civil da Universidade Católica de Pernambuco e no laboratório de Materiais de Construção Civil da Universidade de Pernambuco.

\section{Cimento}

O cimento utilizado para realização dos procedimentos nos concretos em estudo foi o (CP II Z 32), do qual suas propriedades, quando bem analisadas, atendem estruturas em concreto armado, argamassas e concreto para pavimentos. Com adição de material pozolânico que variando de $6 \%$ a $14 \%$ em massa, confere ao cimento menor permeabilidade. A escolha deste tipo de cimento se deu ao fato do mesmo ser o mais comum nos estabelecimentos comerciais da Região Metropolitana do Recife (RMR). A análise física para o cimento, de acordo com informações do fabricante, pode ser visualizada no (Quadro 1) e a caracterização química está apresentada no (Quadro 2).

Quadro 1 - Análise física do aglomerante.

\begin{tabular}{|c|c|c|c|}
\hline Ensaio & Unidade & Resultado & Exigência \\
\hline Área específica (Blaine) & $\mathrm{cm} 2 / \mathrm{g}$ & 3853 & $\geq 3000$ \\
\hline Massa específica & $\mathrm{g} / \mathrm{cm} 3$ & 3,13 & NA \\
\hline Início de pega & minutos & 192 & $\geq 60$ \\
\hline Fim de pega & minutos & 242 & $\leq 600$ \\
\hline Resistência à compressão & $\mathrm{MPa}$ & 29,6 & $\leq 20$ \\
\hline
\end{tabular}

Fonte: Autores, (2021). MPa: Mega Pascal; NA: Não Aplicável 
Quadro 2 - Propriedades químicas do aglomerante.

\begin{tabular}{|c|c|c|c|}
\hline Ensaio & Unidade & Resultado & Exigência \\
\hline Perda ao fogo & $\%$ & 4,83 & $\leq 6,5$ \\
\hline Resíduo insolúvel & $\%$ & 11,56 & $\leq 16,0$ \\
\hline Trióxido de enxofre (SO3) & $\%$ & 2,34 & $\leq 4,0$ \\
\hline Óxido de magnésio (MgO) & $\%$ & 2,67 & $\leq 6,5$ \\
\hline Anidrido carbônico $\left(\mathbf{C O}_{2}\right)$ & $\%$ & 4,12 & $\leq 5,0$ \\
\hline
\end{tabular}

Fonte: Autores, (2021).

\section{Agregado miúdo (areia)}

Foi utilizado agregado miúdo natural, de origem quartzosa da região Metropolitana do Recife em PE. A areia foi adquirida por uma empresa levando em consideração as características físicas da mesma. O material estava em estado úmido e, para tanto, foi preciso corrigir o teor de água da mesma por secagem natural. Para garantir o teor de umidade, $600 \mathrm{~g}$ foi posta na estufa por cerca de $24 \mathrm{~h}$ a uma temperatura de 100 ${ }^{\circ} \mathrm{C} \pm 2{ }^{\circ} \mathrm{C}$ e, após esse procedimento, utilizou-se $300 \mathrm{~g}$ para a realização do ensaio de caracterização granulométrica levando em consideração o ensaio de granulometria do agregado miúdo de acordo com a norma NBR NM 248 (ABNT, 2003). Através da distribuição dos agregados, obteu-se a curva granulométrica dos agregados miúdos naturais, onde apresentou um módulo de finura de 2,59 e diâmetro máximo de 6,3 mm, sendo este classificado como agregado miúdo de granulometria grossa. Os resultados estão representados na (Figura 2).

Agregado reciclado: (resíduo de construção civil)

O resíduo utilizado nesta pesquisa foi concedido por uma empresa de beneficiamento de resíduos da construção e demolição que recebe os RCC's provenientes da Região Metropolitana de Recife. Após a obtenção resíduos o material de descarte foi disposto na máquina Gipo Kombi que fez o processo de trituração. A máquina dispõe de quatro esteiras que funcionam como saídas dos materiais após o processo de trituração, fornecendo assim, quatro diferentes granulometrias: areia grossa, brita $19 \mathrm{~mm}$, brita 25 mm e material de aterro, porém foram coletados o material na granulometria de areia. Foi coletado aproximadamente $100 \mathrm{~kg}$ do agregado reciclado, para serem utilizados como material substituto do agregado miúdo natural e lavados ao laboratório, onde foi 
determinada a composição granulométrica e a massa unitária do resíduo. Para isso foi preciso secar uma fração de 600 gramas do material reciclado na estufa a $100^{\circ} \mathrm{C} \pm 2^{\circ} \mathrm{C} \mathrm{e}$, após esse procedimento, utilizou-se $300 \mathrm{~g}$ para a realização do ensaio de caracterização granulométrica com técnica de vibração, levando em consideração o ensaio de granulometria do agregado miúdo de acordo com a norma NBR NM 248 (ABNT, 2003). Após a classificação granulométrica apresentou módulo de finura de 2,37 inferior ao módulo de finura da areia convencional. O diâmetro máximo das partículas do agregado reciclado foi de $6,3 \mathrm{~mm}$, sendo este classificado como material de granulometria grossa ficando dentro dos limites utilizáveis estabelecidos pela NBR 7211 (ABNT, 2009). Os resultados apresentam-se na (Figura 2).

Figura 2 - Distribuição granulométrica do agregado natural e do (RCC).

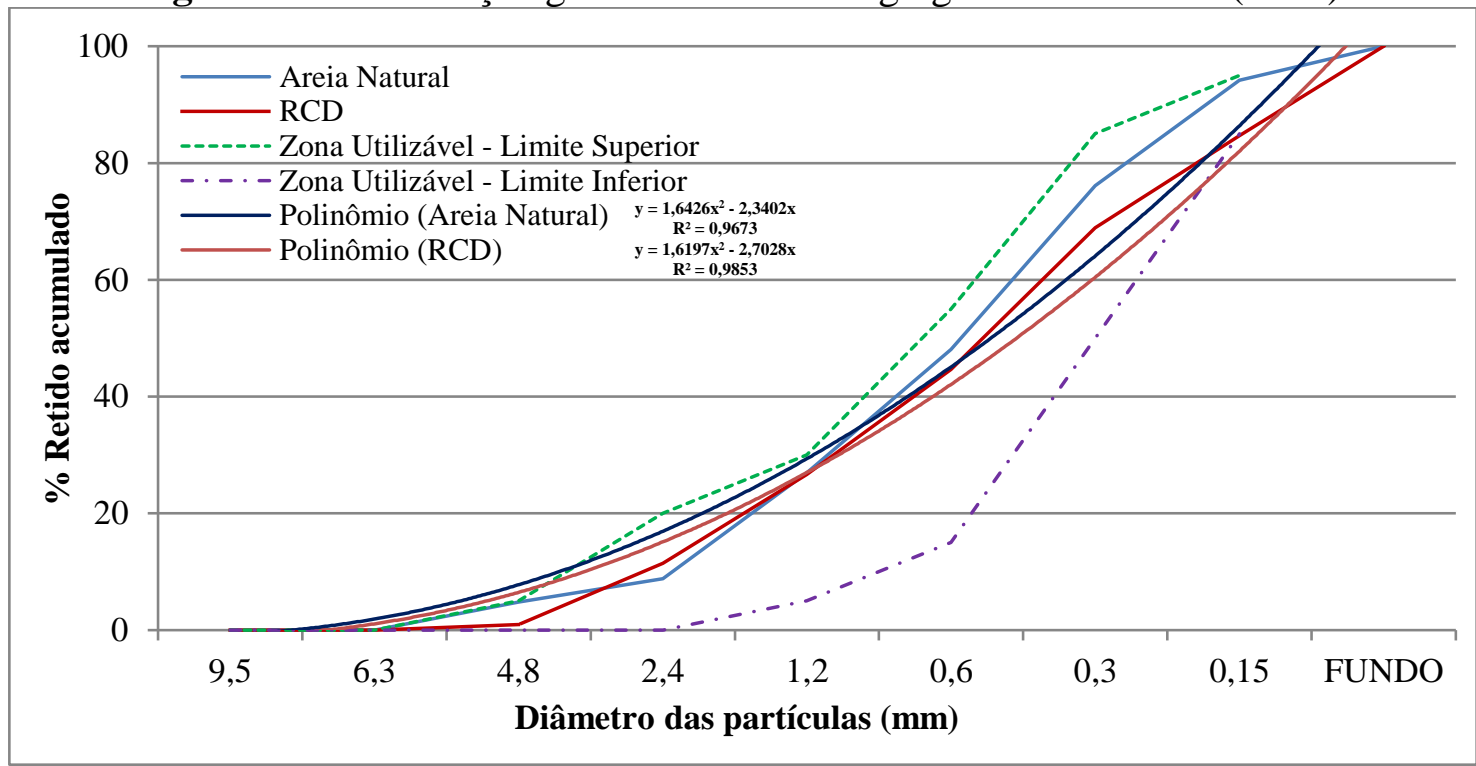

Fonte: Autores, (2021).

Como agregado graúdo, foi utilizada pedra britada de rocha diabásica. As pedras apresentam dimensão máxima de 12,5 mm, compatível com os (CP's) prismáticos com tamanho reduzido. Além disso, também foi obtido a curva granulométrica, mas não se apresenta neste artigo. No (Quadro 3) confere ao material um módulo de finura de aproximadamente 6,46 e diâmetro máximo de $12,5 \mathrm{~mm}$, sendo desta forma, classificado como brita 1 . 
Quadro 3 - Propriedades físicas do agregado graúdo.

\begin{tabular}{|c|c|c|c|c|}
\hline & sticas & Método do ensaio & \multicolumn{2}{|c|}{ BRITA 1} \\
\hline \multicolumn{2}{|c|}{ Massa específica $\left(\mathrm{g} / \mathrm{cm}^{3}\right)$} & NM 53 (ABNT, 2009) & \multicolumn{2}{|c|}{2,64} \\
\hline \multicolumn{2}{|c|}{ Massa unitária $\left(\mathrm{g} / \mathrm{cm}^{3}\right)$} & NBR 45 (ABNT, 2006) & \multicolumn{2}{|c|}{1,45} \\
\hline \multicolumn{2}{|c|}{$\begin{array}{l}\text { Dimensão máxima característica } \\
(\mathrm{mm})\end{array}$} & NM 248 (ABNT, 2003) & \multicolumn{2}{|c|}{12,5} \\
\hline \multicolumn{2}{|c|}{ Módulo de finura } & NM 248 (ABNT, 2003) & \multicolumn{2}{|c|}{6,46} \\
\hline \multicolumn{2}{|c|}{ Abertura da peneira $(\mathrm{mm})$} & \multirow{7}{*}{ NM 248 (ABNT, 2003) } & $\begin{array}{l}\text { Porcentagem } \\
\text { retida }(\%)\end{array}$ & $\begin{array}{c}\text { Porcentagem } \\
\text { acumulada }(\%)\end{array}$ \\
\hline \multirow{6}{*}{ 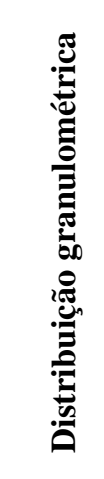 } & 19,0 & & 0,00 & 0,00 \\
\hline & 12,5 & & 0,58 & 0,58 \\
\hline & 9,5 & & 11,96 & 12,54 \\
\hline & 6,3 & & 48,23 & 60,77 \\
\hline & 4,8 & & 20,66 & 81,43 \\
\hline & 2,4 & & 16,01 & 97,44 \\
\hline
\end{tabular}

Fonte: Autores, (2021).

\section{Corpos-de-prova prismáticos}

Os (CP's) utilizados na pesquisa, foram definidos em função do planejamento experimental e levando em consideração a disponibilidade de espaço físico da estufa utilizada, da câmara de aceleração de $\left(\mathrm{CO}_{2}\right)$. A confecção dos (CP's) para os ensaios de indução de difusão de $\left(\mathrm{CO}_{2}\right)$ através da câmara de carbonatação segue, em linhas gerais, o modelo empregado por Monteiro (2002). A concepção consiste em utilizar forma prismática em madeira com dimensões reduzidas, empregando-se 2 (duas) armaduras dispostas com bitola de $\emptyset 6 \mathrm{~mm}$ e cobrimentos de 2,5 cm. Os corpos-de-prova, do presente trabalho, são de seção retangular com dimensões fixas de $(10 \mathrm{~cm}$ x $10 \mathrm{~cm}$ x 6 $\mathrm{cm}$ ), conforme mostrado na (Figura 3). 
Figura 3 - Vista superior e lateral das formas utilizadas.

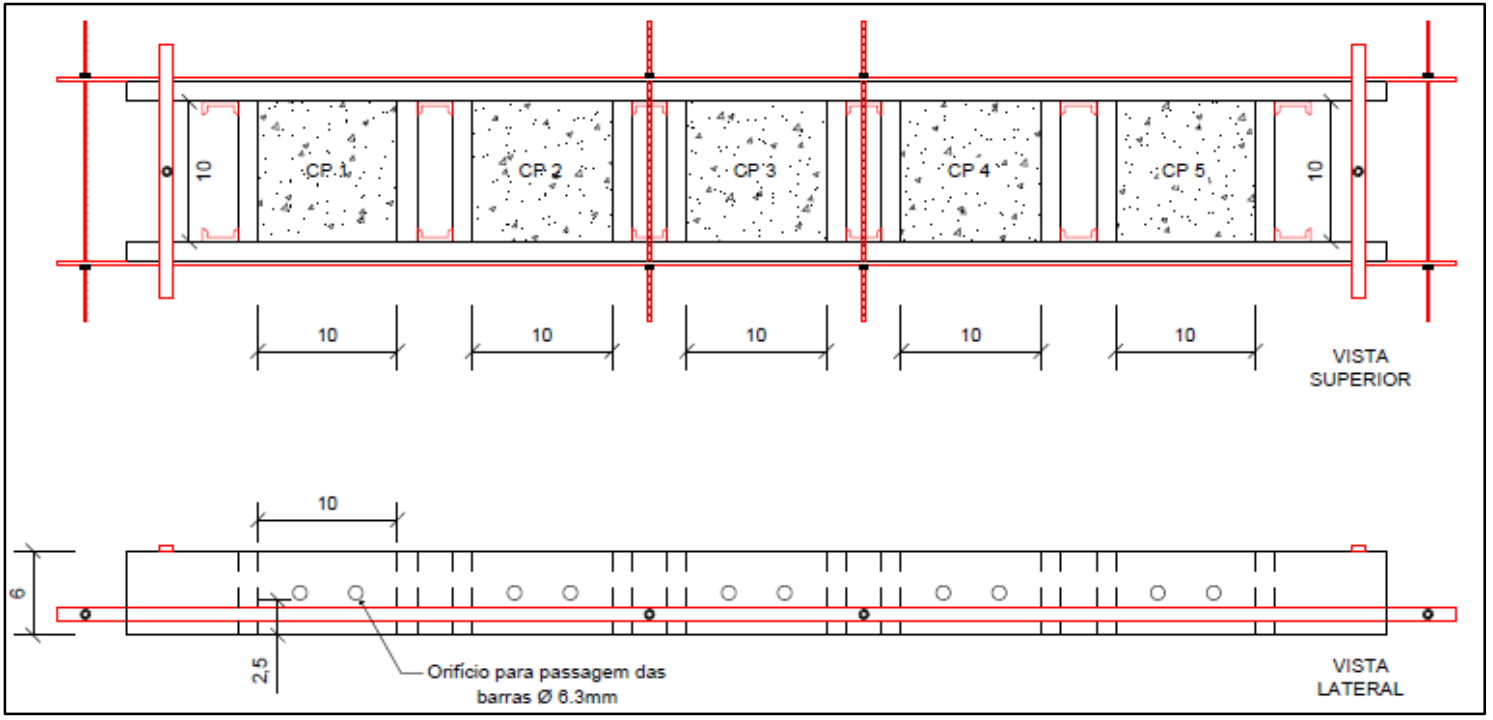

Fonte: Marques, (2018).

\section{Câmara de carbonatação}

O procedimento do ensaio consiste em introduzir uma quantidade de $\left(\mathrm{CO}_{2}\right)$ em um compartimento fechado. A introdução do dióxido de carbono se dá através de um orifício situado na parte inferior da câmara, fazendo com que os gases se desloquem da parte inferior da câmara até a saída situada na parte superior da mesma como visto nas (Figuras 4)

Figura 4 - (a) Esquema da câmara de carbonatação.

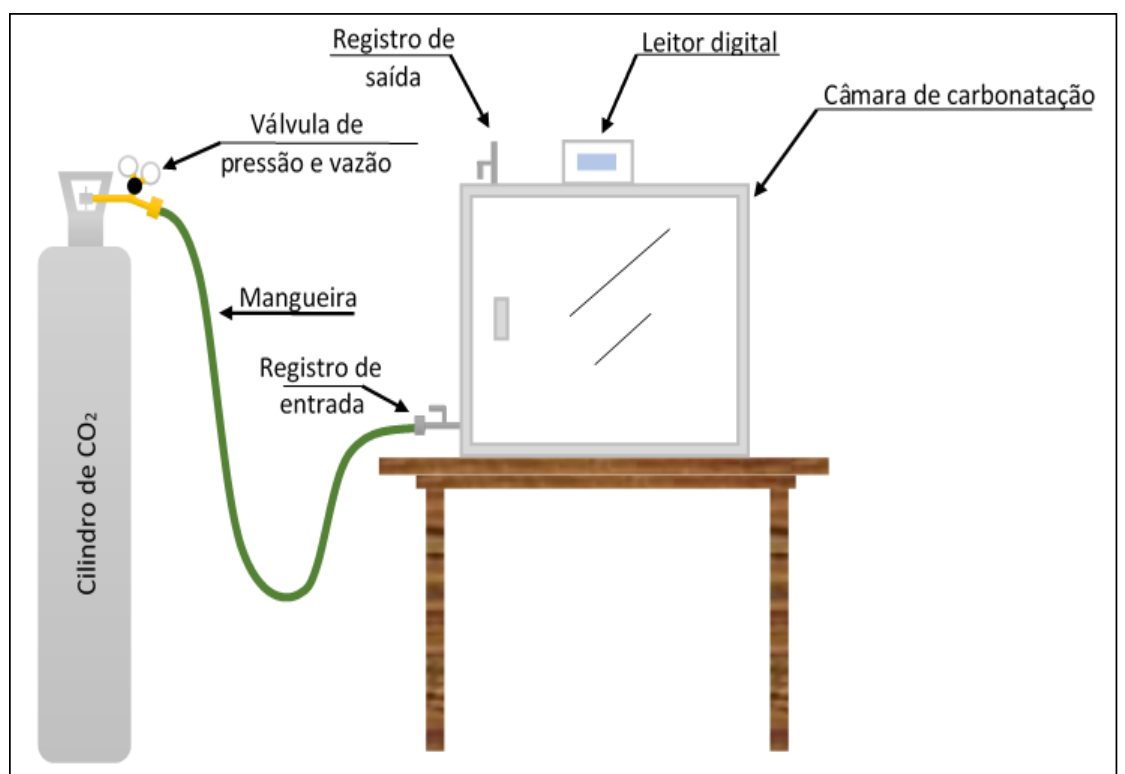

Fonte: Autores, (2021). 
A câmara de carbonatação foi desenvolvida em cantoneira de alumínio em L de 5 $\mathrm{cm}$ suas paredes são em folhas de PVC revestida em fórmica, e possui aproximadamente 100 litros, onde a saída e entrada de ar possuem registros para controle do fluxo. A vedação da câmara foi feita com silicone. O sistema utilizado para regular a pressão e a vazão do $\left(\mathrm{CO}_{2}\right)$ é composto por um cilindro de $\left(\mathrm{CO}_{2}\right)$ de $10 \mathrm{~kg}$ acoplado em um regulador de vazão e pressão. Após o regulador de pressão foi colocada uma mangueira de silicone para injeção de $\left(\mathrm{CO}_{2}\right)$ na câmara. A câmara também é dotada de um sistema de controle, para monitoramento das variáveis, concentração de dióxido de carbono, temperatura e umidade no interior da mesma durante o ensaio desenvolvido com arduíno e programação $\mathrm{C}++$.

A metodologia executada para a exposição dos (CP's) à ação do $\left(\mathrm{CO}_{2}\right)$ na câmara de carbonatação acelerada irá ocorrer na exposição dos (CP's) a aproximadamente 70\%$100 \%$ de dióxido de carbono dentro da câmara, sendo feitas leituras do potencial de corrosão a cada sete dias, por aproximadamente 30 dias de exposição ao $\left(\mathrm{CO}_{2}\right)$ obtendo o processo de evolução da carbonatação. A inserção de gás carbônico ocorreu de forma manual. A válvula de pressão foi acionada, posicionando-a em um valor de aproximadamente 70 , em seguida a válvula de vazão foi acionada também marcando a posição em 10. Foi marcado 10 minutos após a válvula de vazão ser aberta, e durante cerca de 10 minutos acredita-se que a câmara possuía cerca de $100 \%$ de $\left(\mathrm{CO}_{2}\right)$. Ao final do período, os corpos-de-prova foram rompidos para a realização do ensaio colorimétrico de aspersão da solução fenolftaleína, indicador de $\mathrm{pH}$, para analisar o avanço da contaminação quanto à frente de carbonatação no interior do concreto.

\section{Traço utilizado}

Levando em consideração todas as características físicas dos componentes para a produção dos concretos e, além disso, o traço unitário dado pela representação (C : A : B : A/C), sabe-se que, para $1 \mathrm{~m}^{3}$, tem-se 390,20 kg relativo ao consumo de ( $\left.\mathrm{C}_{\text {cimento }}\right), 683,00$ $\mathrm{kg}$ referente ao agregado miúdo ( $\left.\mathrm{A}_{\text {areia }}\right), 1073,00 \mathrm{~kg}$ de agregado graúdo ( $\mathrm{B}_{\text {brita }}$ ) e uma relação água/cimento $(\mathrm{A} / \mathrm{C})$ de 0,55 que equivale a 2051 de água, caracterizado pelo traço unitário $1: 1,75: 2,75: 0,55$. Além desses dados, o teor de argamassa $(\alpha)$ foi de aproximadamente 0,5 . Para a relação água/cimento utilizada, a resistência à compressão estimada é $\leq 30 \mathrm{Mpa}$. O desvio padrão (Sd) utilizado para cálculo foi de 4,0 e o abatimento teórico de tronco de cone (slump test) foi de $70 \mathrm{~mm} \pm 10 \mathrm{~mm}$. Diante disso, a partir do 
traço de referência (REF), foram produzidos outros três traços, realizando a substituição parcial de $15 \%, 25 \%$ e $50 \%$ do agregado natural miúdo (areia) por (RCC), onde as características estão apresentadas no (Quadro 4).

Quadro 4 - Resumo dos corpos-de-prova de concreto (concreto + aço).

\begin{tabular}{|c|c|c|c|}
\hline Tipo & Quantidade (UND) & Cobrimento (CM) & Armadura (Ø mm) \\
\hline 0\% Referência & 20 & 2,5 & 6,3 \\
\hline $15 \%$ de RCC & 20 & 2,5 & 6,3 \\
\hline $25 \%$ de RCC & 20 & 2,5 & 6,3 \\
\hline $50 \%$ de RCC & 20 & 2,5 & 6,3 \\
\hline
\end{tabular}

Fonte: Autores, (2021).

As barras de aço utilizadas, foram higienizadas de acordo com a norma internacional ASTM G1-03 (ASTM, 2017). As barras foram cortadas no tamanho de 15 cm, depois foram dispostas em solução feita com $500 \mathrm{ml}$ de Ácido Clorídrico, 3,5 g de Hexametilenotetramina e 1L de água por 15 minutos. Em seguida, as barras foram lavadas em água corrente e com auxílio de escovas de aço foi feita a remoção da camada de óxido e de impurezas.

\section{Moldagem e cura}

Os materiais utilizados para a confecção dos corpos-de-prova foram devidamente pesados e levados à betoneira. Primeiro o agregado graúdo foi adicionado na betoneira com aproximadamente $2 / 3$ da água pesada e foram homogeneizados durante 1 minuto. Após isso adicionou-se o cimento, o agregado miúdo natural e o 1/3 da água restante, onde os mesmos foram dispostos por 5 minutos para homogeneização. Passando essas etapas, o material foi disposto numa cuba metálica e em seguida foi-se realizado o ensaio de abatimento de tronco de cone de acordo com a NBR NM 67 (ABNT, 1998) para depois serem moldados. As fôrmas dos (CP's) prismáticos foram preparados com desmoldante para que o concreto não aderisse às paredes dos moldes utilizados e, assim, foi feita a disposição das barras de aço nas aberturas de $\varnothing 6.3 \mathrm{~mm}$. Além disso, foi feito o adensamento do concreto de forma manual utilizando o soquete, realizando 25 golpes em cada uma das três camadas. Assim que foram moldados, colocou-se uma lona plástica para evitar retração por evaporação e exsudação da água por percolação e os deixou em cura por 24 horas como pode ser visto na (Figura 5 (a), (b) e (c)). 
Figura 5 - (a) Corpos-de-prova com lona plástica; (b) Corpos-de-prova sem a fita; (c) Corpos-de-prova com a fita isolante.

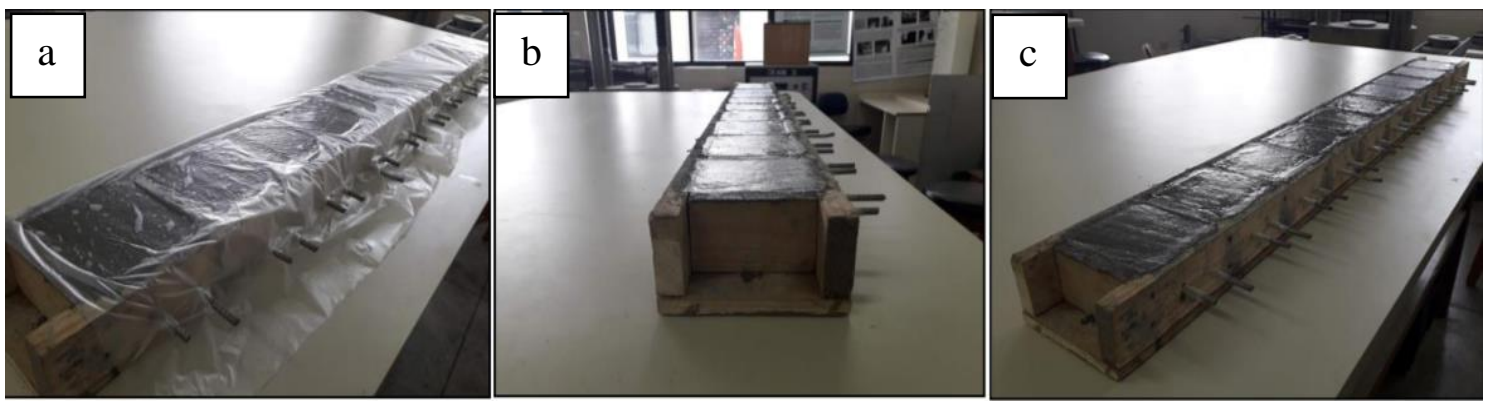

Fonte: Autores, (2021).

A fim de garantir a integridade das armaduras à mostra, as mesmas foram isoladas com fita. Posteriormente foram desmoldados e submetidos a cura úmida por 28 dias seguidos a partir da data da moldagem. Transcorridos os 28 dias de cura, os corpos-deprova iniciaram um procedimento de secagem ambiente no laboratório por 30 dias para que os vazios fossem preenchidos por ar. Após isso, foram conectados fios flexíveis à extremidade livre das armaduras, para as medidas dos futuros potenciais de corrosão, além disso, essa conexão foi protegida com fita isolante resistente. As medições dos potenciais de corrosão foram realizadas antes de iniciar a indução do dióxido de carbono $\left(\mathrm{CO}_{2}\right)$, onde os mesmos serviram para as análises comparativas e, sobretudo, da capacidade de o concreto resistir ao agente agressivo. Para cada corpo-de-prova foram realizadas 3 (três) medições em cada barra, sabendo então, que uma das 6 (seis) faces do corpo-de-prova prismático foi impermeabilizada com tinta de emulsão asfáltica. Os potenciais de corrosão obtidos para os corpos-de-prova ao longo do tempo foram esboçados em gráficos $(\mathrm{X}, \mathrm{Y})$ onde tem-se o potencial de corrosão versus o tempo em dias da indução do $\left(\mathrm{CO}_{2}\right)$ na câmara de carbonatação acelerada por aproximadamente 30 dias.

\section{Potencial de corrosão}

A medida do potencial de corrosão de meia célula tem como base medir a velocidade e evolução do processo corrosivo da armadura, obtendo o potencial de corrosão através de um eletrodo de referência, o qual indica aproximadamente a probabilidade de ocorrência da corrosão e a consequente classificação do estado do concreto (KHAN; AHMAD; ALGAHTANI, 2017). Segundo a norma C 876 (ASTM, 2015) o método de ensaio para obtenção de potenciais de corrosão em concreto, tem seu uso permitido em ensaios laboratoriais, ou em análises de campo. Os critérios para interpretação dos resultados obtidos, nas medidas de potencial de corrosão, estão 
descritos no (Quadro 5) e indicam a probabilidade de ocorrência da corrosão na região ensaiada. A solução preparada para preencher o eletrodo foi a proporção de 40 unidades de peso de Sulfato de cobre para 100 unidades por peso de água destilada, onde para o equipamento utilizado foi realizado uma solução de $40 \mathrm{ml}$ de água destilada para $16 \mathrm{~g}$ de Sulfato de cobre aplicado, sendo esta quantidade essencial para o preenchimento do eletrodo. Posteriormente, o eletrodo é apoiado verticalmente sobre a superfície do concreto nos locais onde se encontram as armaduras, sendo esses locais medidos três vezes em pontos diferentes, sendo que as leituras foram realizadas por um voltímetro de alta impedância. Assim, foram alocados seis pontos de medição em cada corpo de prova, onde estas medições foram realizadas nos (CP's) antes de iniciar a indução da penetração do dióxido de carbono e ao término de cada indução como pode ser avistado na (Figura 6). Além disso, as medidas foram comparadas com as taxas de probabilidade de corrosão de acordo com (Quadro 5).

Figura 6 - Realização da medição do potencial de corrosão.

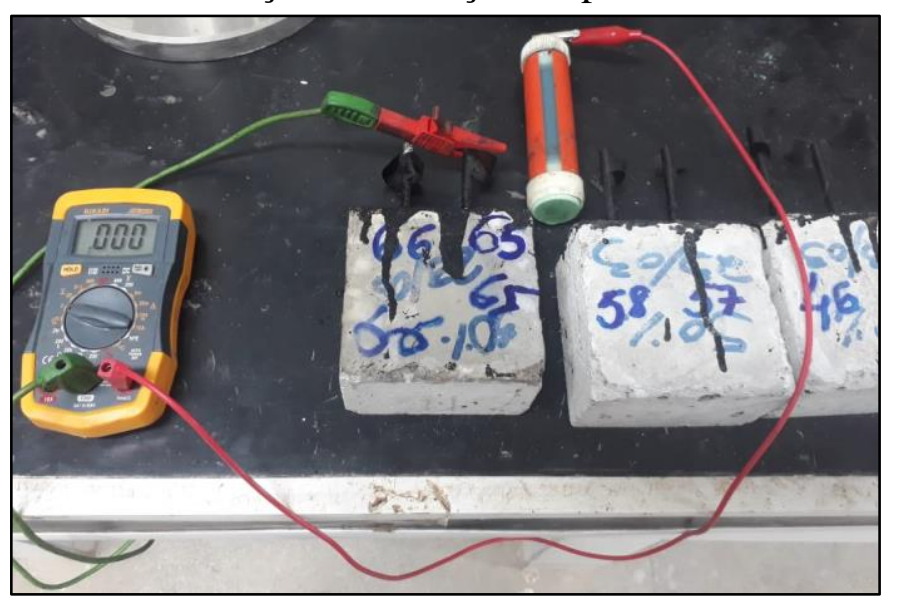

Fonte: Autores, (2021).

Quadro 5 - Faixas de potencial de corrosão e a relação de probabilidade de corrosão.

\begin{tabular}{|c|c|}
\hline Eletrodo de cobre/ Sulfato de cobre & Probabilidade de corrosão \\
\hline Mais negativo que $-350 \mathrm{mV}$ & Superior a $90 \%$ \\
\hline Mais positivo que $-200 \mathrm{mV}$ & Inferior a $10 \%$ \\
\hline De $-200 \mathrm{mV}$ a $-35 \mathrm{mV}$ & Incerta \\
\hline
\end{tabular}

Fonte: C 876, (ASTM 2015). 


\section{RESULTADOS E DISCUSSÕES}

\section{Teor de materiais pulverulentos}

A areia natural apresentou teor de material pulverulento de $7 \%$ enquanto o RCC apresentou uma taxa de $15,5 \%$, apresentando um aumento de mais de $50 \%$ em relação ao agregado natural. Apesar do RCC apresentar teor de material pulverulento de 15,5\%, este resultado confere a este material a permanência dentro do limite estabelecido pela norma de agregados reciclados de resíduos sólidos da construção civil, NBR 15116 (ABNT, 2004), não ultrapassando $20 \%$.

\section{Potencial de corrosão}

Levando em consideração algumas variáveis como exposição dos CP's a temperatura ambiente, os materiais do concreto convencional e os traços com a utilização do RCC tem-se as medições médias dos potenciais de corrosão para cada traço como mostrado na (Quadro 6).

Quadro 6 - Potenciais médios ao longo do ensaio de carbonatação acelerada.

\begin{tabular}{|c|c|c|c|c|}
\hline \multirow{2}{*}{$\begin{array}{c}\text { Família/ } \\
\text { Tempo }\end{array}$} & \multicolumn{4}{|c|}{ Potencial de corrosão (mV) } \\
\cline { 2 - 5 } & $\begin{array}{c}\text { (CP's) de } \\
\text { referência }\end{array}$ & $\begin{array}{c}\text { (CP's) com 15\% de } \\
\text { RCC }\end{array}$ & $\begin{array}{c}\text { (CP's) com 25\% de } \\
\text { RCC }\end{array}$ & $\begin{array}{c}\text { (CP's) com 15\% de } \\
\text { RCC }\end{array}$ \\
\hline M0 & -121 & -106 & -103 & -109 \\
\hline $\mathbf{7}$ dias & -163 & -136 & -166 & -255 \\
\hline $\mathbf{1 4}$ dias & -206 & -178 & -268 & -256 \\
\hline $\mathbf{2 1}$ dias & -256 & -295 & -310 & -312 \\
\hline $\mathbf{2 8}$ dias & -321 & -355 & -352 & -370 \\
\hline
\end{tabular}

Fonte: Autores, (2021).

Pode-se observar no quadro a evolução dos resultados referentes as leituras do potencial de corrosão $\left(\mathrm{E}_{\text {corr }}\right)$ ao longo de 30 dias, onde o M0 é a medição inicial e os 28 dias são as medições do concreto de referência, com 15\% de RCC, $25 \%$ de RCC e com $50 \%$ de RCC. O ensaio de potencial de corrosão ( $\mathrm{E}_{\text {corr }}$ ) é utilizado para determinar, quantificar e qualificar o comportamento do aço em função do concreto quanto a durabilidade. Desta forma, essas análises são realizadas afim de compreender a ação da 
difusão do dióxido de carbono no concreto e, o quanto esse agente agressivo podem degradar a estrutura.

Os resultados mostram nitidamente que os corpos-de-prova de referência apresentam valores mais negativos de potencial de corrosão na evolução do ensaio de carbonatação acelerada. Para tanto, verifica-se os resultados mais satisfatórios, atingindo, no final de 28 dias, um valor de $-321 \mathrm{mV}, 62 \%$ maior quando comparado ao valor $\mathrm{M} 0$ que corresponde a $-121 \mathrm{mV}$ como pode ser visto na (Figura 7), indicando a incerteza de condição favorável para ocorrência de corrosão generalizada das barras de aço.

Figura 7 - Resultados das leituras do potencial de corrosão para os (CP's) de referência.

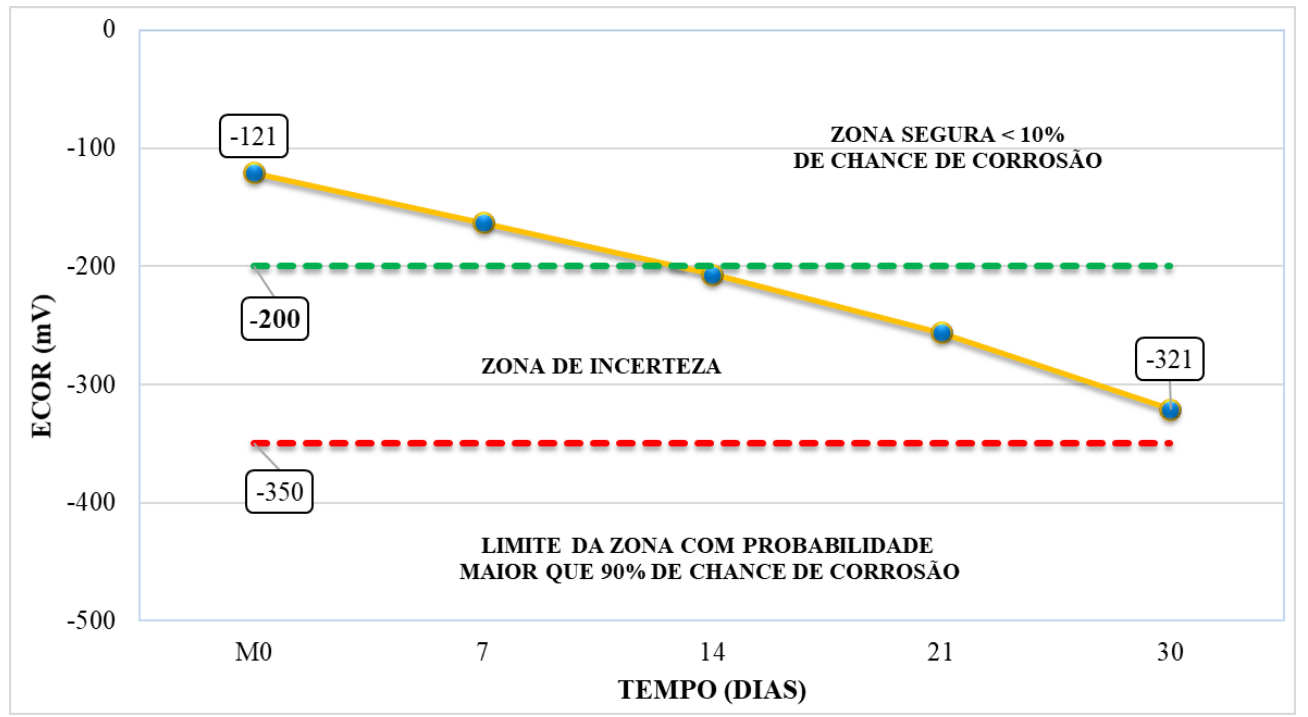

Fonte: Autores, (2021).

Nunes (2014), trouxe em seu estudo resultados semelhantes ao comportamento do concreto frente a difusão acelerada de $\left(\mathrm{CO}_{2}\right)$, onde observou que em 7 dias de carbonatação acelerada, o potencial de corrosão aumentou devido a unidade interna do material utilizado. Além disso, os autores Morla et al., (2021) relataram que há um "limite crítico" no comportamento da carbonatação quando se utiliza uma relação água/ cimento de 0,55 .

Os estudos corroboram com os resultados obtidos por Naik, Narendranath e Kumar (2020), pois um dos fatores evidenciados por ele foi a relação água/cimento utilizada de 0,55. Assim, para essa relação água/ cimento as características químicas desempenham um papel significativo na profundidade de carbonatação e o consumo de 
$\mathrm{Ca}(\mathrm{OH})_{2}$ influenciam de forma direta na corrosão generalizada das armaduras e a fixação do $\left(\mathrm{CO}_{2}\right)$, onde, por sua vez, aumenta o potencial eletronegativo das amostras estudadas.

Diferente dos (CP's) de referência, os concretos com 15\% de RCC em sua matriz, apresentaram maior eletronegatividade aos 30 dias, com valor de $-335 \mathrm{mV}$, que, segundo a norma, indica que as barras de aço na região interna destes concretos apresentam uma probabilidade de $90 \%$ de terem iniciado o processo de corrosão como pode ser visto na (Figura 8).

Apesar de o resultado conferir aos concretos desta família uma probabilidade incerta na ocorrência de corrosão após exposição ao $\left(\mathrm{CO}_{2}\right)$, nota-se um valor mais eletronegativo do que o concreto referência, além de apresentar uma redução brusca entre o período de 14 a 21 dias, demonstrando uma instabilidade do concreto em resistir à ação deste agente agressivo. Para tanto, ao observar o comportamento dos corpos-de-prova diante da exposição da difusão acelerada de $\left(\mathrm{CO}_{2}\right)$, percebeu-se que ao término do ensaio houve um aumento da probabilidade de corrosão de aproximadamente $70 \%$ quando comparado com o valor $-106 \mathrm{mV}$, valor inicialmente obtido.

Figura 8 - Resultados das leituras do potencial de corrosão para os (CP's) com 15\% de (RCC).

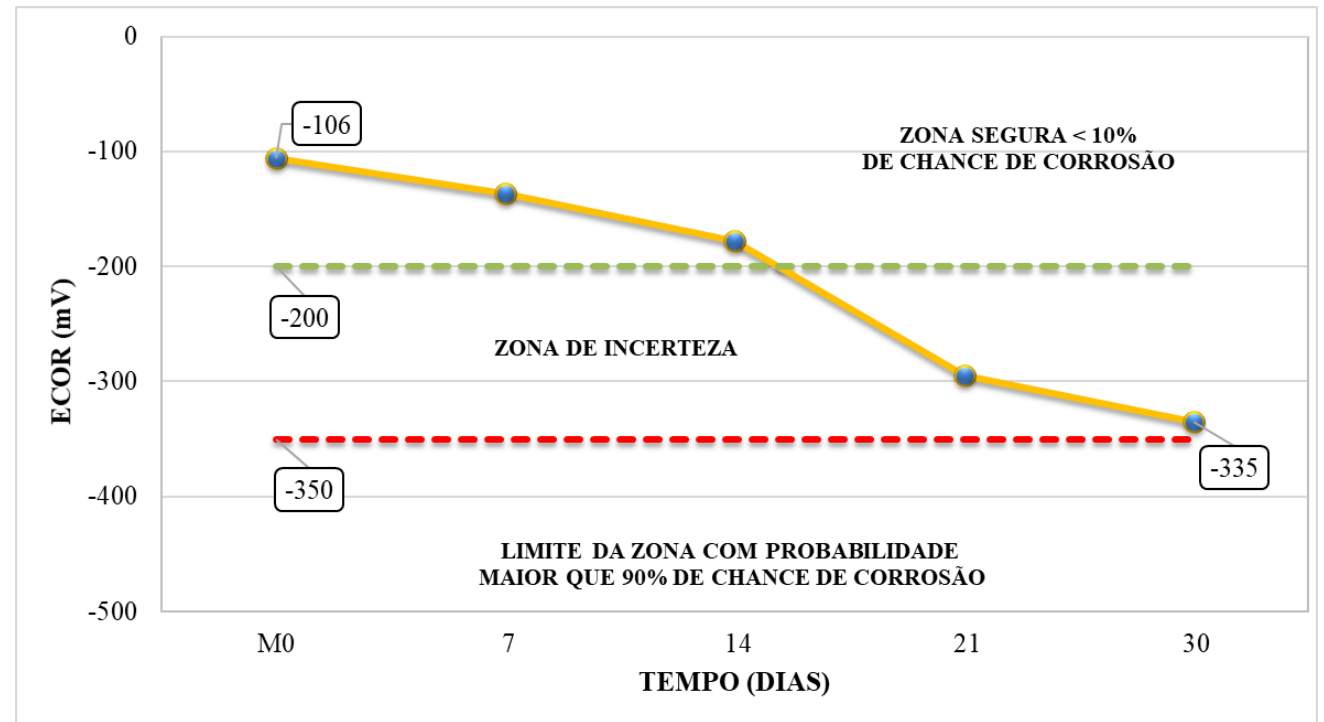

Fonte: Autores, (2021).

Além disso, um outro fator que pode ter influenciado no aumento do potencial de corrosão foi a relação (a/c), pois observou-se no estudo granulométrico que o RCC possui um índice de finos maior, potencializando o aumento da superfície específica. $\mathrm{O}$ traço de referência teve um melhor trabalhabilidade, adensamento e menor índice de vazios, ou 
seja, essa relação água/cimento foi considerada ideal tanto para o traço de com nenhuma substituição, tanto para o traço com 15\% contendo RCC. Segundo Mcdonald et al., (2020) e Tran et al., (2020), os valores de potencial de corrosão fixam-se entre a zona de incerteza e o valor mais eletronegativo entre 14 e 30 dias.

Diante das análises realizadas, pode-se observar na (Figura 9), que a leitura do potencial de corrosão aos 30 dias foi $-352 \mathrm{mV}$, valor este que poderia ser desconsiderado para efeito de probabilidade de corrosão já que foi apenas $-2 \mathrm{mV}$ de diferença quando se trata da zona de incerteza. Nesse sentido, observa-se que houve um aumento de aproximadamente $71 \%$ de corrosão generalizada quando comparado ao resultado inicial que foi de $-103 \mathrm{mV}$.

Figura 9 - Resultados das leituras do potencial de corrosão para os (CP's) com 25\% de (RCC).

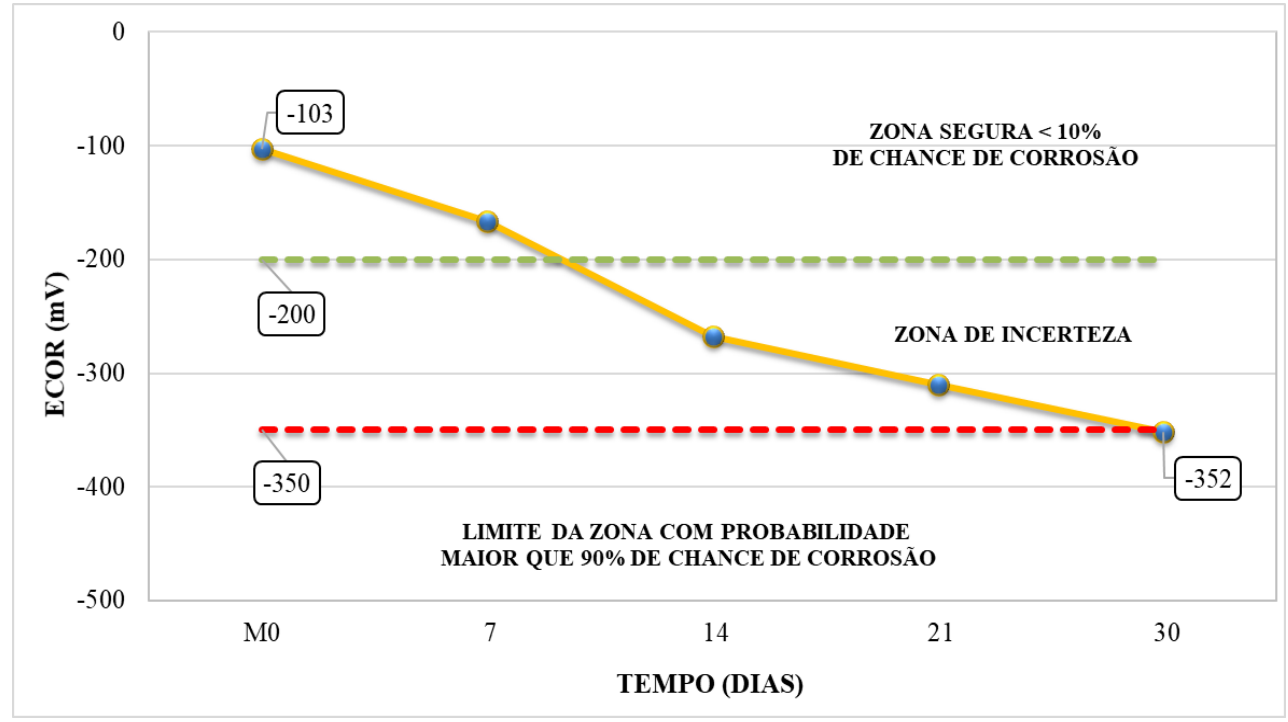

Fonte: Autores, (2021).

Analisando os resultados, observa-se que o traço de $25 \%$ em relação ao traço de $15 \%$ é mais eletronegativo aproximadamente 5\%. Mais uma vez comprova que a superfície específica, a relação água/cimento - (a/c), o número de finos e a resistividade interferem diretamente no comportamento do concreto em função da coesão, índice de vazios e a possível segregação dos materiais vistos nos traços que possuíam RCC em sua composição.

Para o estudo realizado, o comportamento do concreto com $25 \%$ de RCC iniciou seu limite de corrosão, mas o ensaio foi monitorado em apenas 1 mês. Diante disso, sabese que no decorrer de 90 dias, o processo de difusão acelerada de $\left(\mathrm{CO}_{2}\right)$ iria potencializar 
gerando, provavelmente perda de seção da armadura. Estudos realizados por Vieira et al., (2010) não corroboram com os obtidos nesse estudo, pois deixam claro que a diferença de potencial de $-350 \mathrm{mV}$ fixou-se entre a zona de incerteza e o valor da leitura obtida no estudo em 63 dias. Desta forma, percebe-se que é bem menor do que poderia se obter em um tempo de exposição maior nos estudos realizados.

No que tange aos valores das leituras obtidas nos corpos-de-prova com 50\% de RCC, foi observado um maior resultado eletronegativo aos 28 dias conforme mostrado na (Figura 10). Com o resultado de $-370 \mathrm{mV}$ estes concretos podem ser classificados com $90 \%$ de chance de as barras terem iniciado o processo de corrosão.

Figura 10 - Resultados das leituras do potencial de corrosão para os (CP’s) com 50\% de (RCC).

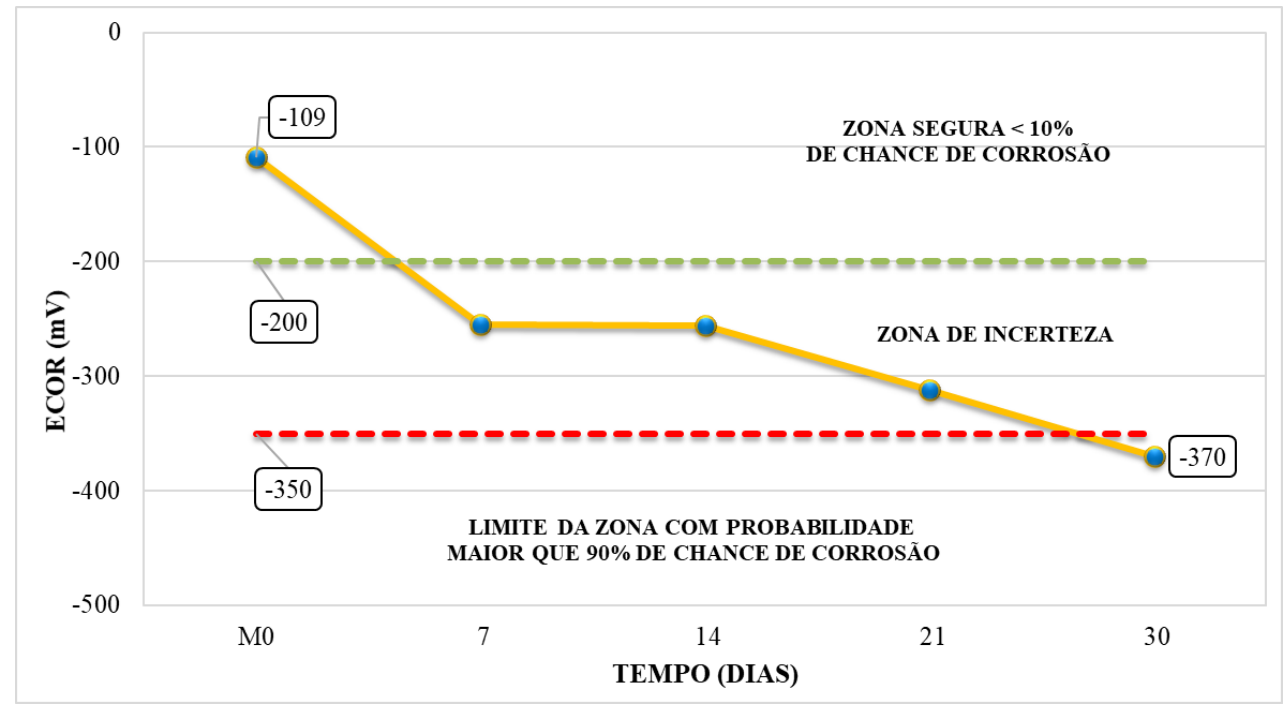

Fonte: Autores, (2021).

Ao analisar o comportamento dos (CP's) em relação a durabilidade frente a exposição do concreto ao dióxido de carbono $\left(\mathrm{CO}_{2}\right)$, os concretos com $50 \%$ de substituição não apresentaram uma boa coesão impossibilitando uma melhor vibração, tendo como consequência a segregação dos componentes, havendo então, maiores índices de vazios que facilitam a contaminação das armaduras através da difusão do dióxido de carbono.

Este fenômeno pode estar relacionado à quantidade de finos, e grande quantidade de materiais cimentícios antigos no material reciclado, promovendo um concreto poroso, o que facilita o ingresso do $\left(\mathrm{CO}_{2}\right)$. Como a carbonatação está intimamente relacionada à porosidade por causa do alto teor de materiais pulverulentos, a incorporação de agregado 
reciclado possibilitará um concreto mais permeável e, portanto, maiores profundidades de carbonatação conforme observado por Samson et al., (2020) e Sohail et al., (2021).

A saturação possibilitou a baixa resistividade da massa do concreto, tendendo a valores de $\left(\mathrm{E}_{\text {corr }}\right)$ menos eletropositivos, destacando que a redução da diferença de potencial não pode ser sempre atribuída a despassivação da camada protetora das armaduras, mas sim ao tempo de exposição e tamanho dos grãos. Para melhor contextualizar esse ponto, na (Figura 11 (a) e (b)), pode-se perceber que os (CP's) com $50 \%$ de (RCC) tiveram resultados significativos a 5\% de variância mostrados no diagrama de Pareto.

Figura 11 - (a) Variáveis que influenciam o potencial de corrosão (b) diagrama de Pareto.

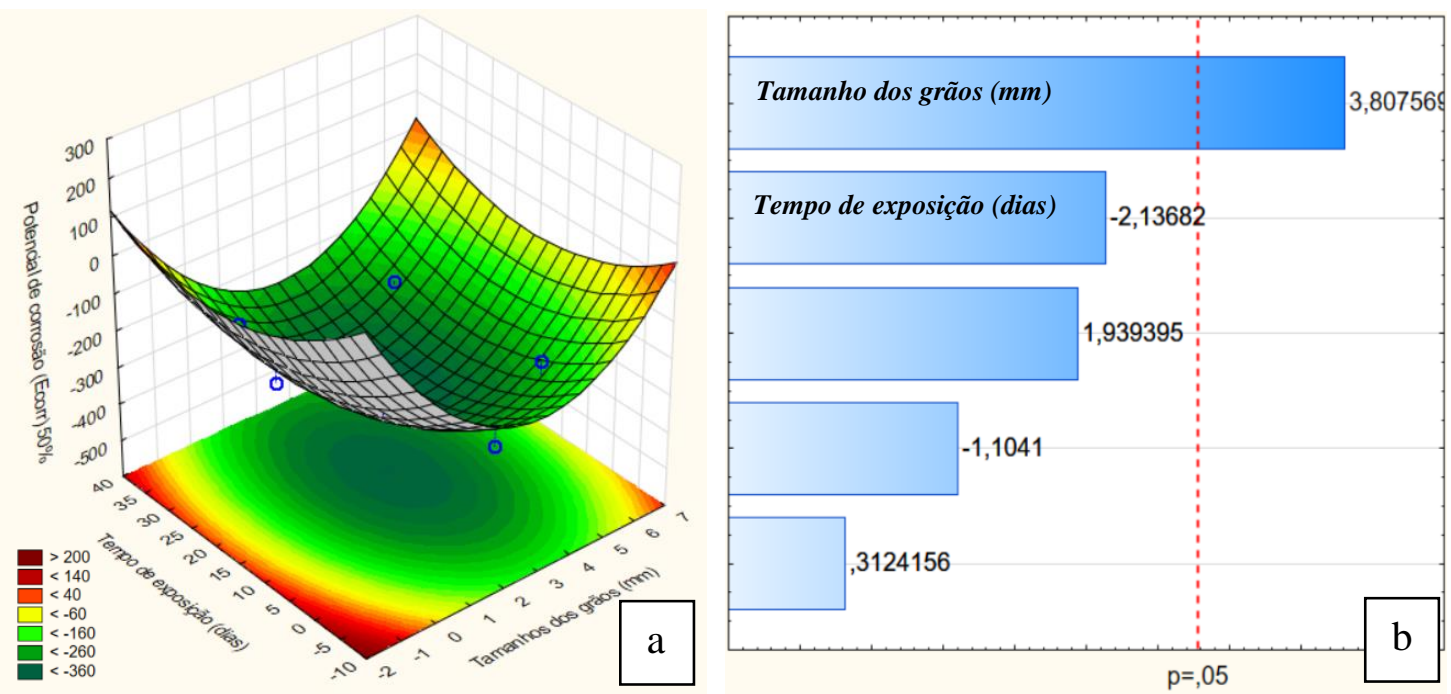

Fonte: Autores, (2021).

A variável com maior influência no processo de difusão da carbonatação é o tempo de exposição na câmara de difusão de dióxido de carbono, bem como o tamanho dos grãos, indicando que o conteúdo de materiais finos evidenciou a difusão de $\left(\mathrm{CO}_{2}\right)$, devido à região de transição das partículas, que se tornaram menos coesas devido a segregação dos agregados no interior da matriz cimentícia. A partir dos valores obtidos na última medição dos (CP's) de referência, 15\%, 25\% e 50\% de substituição parcial obtidos através do ensaio de potencial de corrosão, foi preciso realizar uma análise estatística através do histograma e ANOVA do qual foi obtido de acordo com o método de fator duplo sem repetição. 
O objetivo da análise é compreender a significância dos resultados como pode ser visto na (Figura 12). Observa-se que os resultados são estatisticamente diferentes de acordo com o valor-P que é menor do que 5\% $(0,03), \mathrm{F}(1,93)>$ Fcrítico $(1,78)$ e pela dispersão dos dados em vermelho.

Figura 12 - Resultados da análise da distribuição normal.

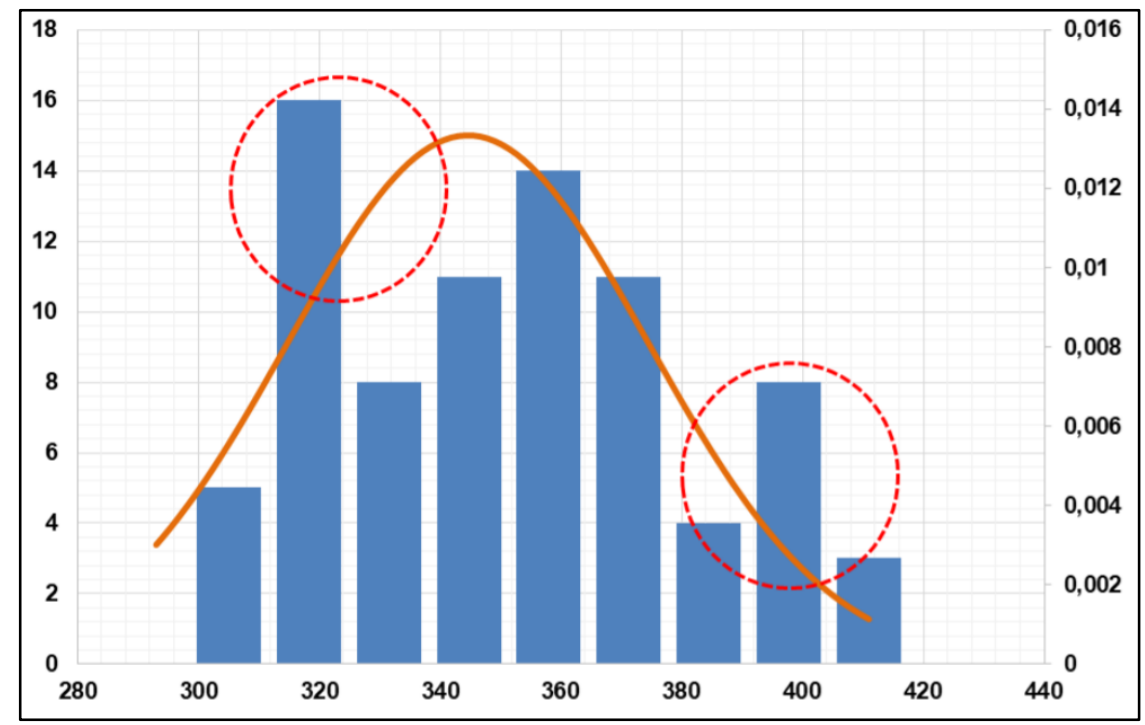

Fonte: Autores, (2021).

Método colorimétrico de aspersão de fenolftaleína

Após o término das medições do potencial de corrosão, foi feita a determinação da profundidade de carbonatação através do indicador de $\mathrm{pH}$ fenolftaleína. Esse ensaio tem o objetivo de auxiliar na medição da profundidade de carbonatação interna do concreto frente a presença de $\left(\mathrm{CO}_{2}\right)$. A solução do indicador de $\mathrm{pH}$ foi preparada com $1 \mathrm{~g}$ de fenolftaleína misturada em $100 \mathrm{ml}$ de álcool etílico. Todos os corpos de prova foram rompidos e aspergidos em uma das suas faces com a solução química, posteriormente foi feita a medição da profundidade de carbonatação que visa a complementação do ensaio de potencial de corrosão como pode ser visto na (Figura 13). 
Figura 13 - Corpos-de-prova com aspersão de fenolftaleína.

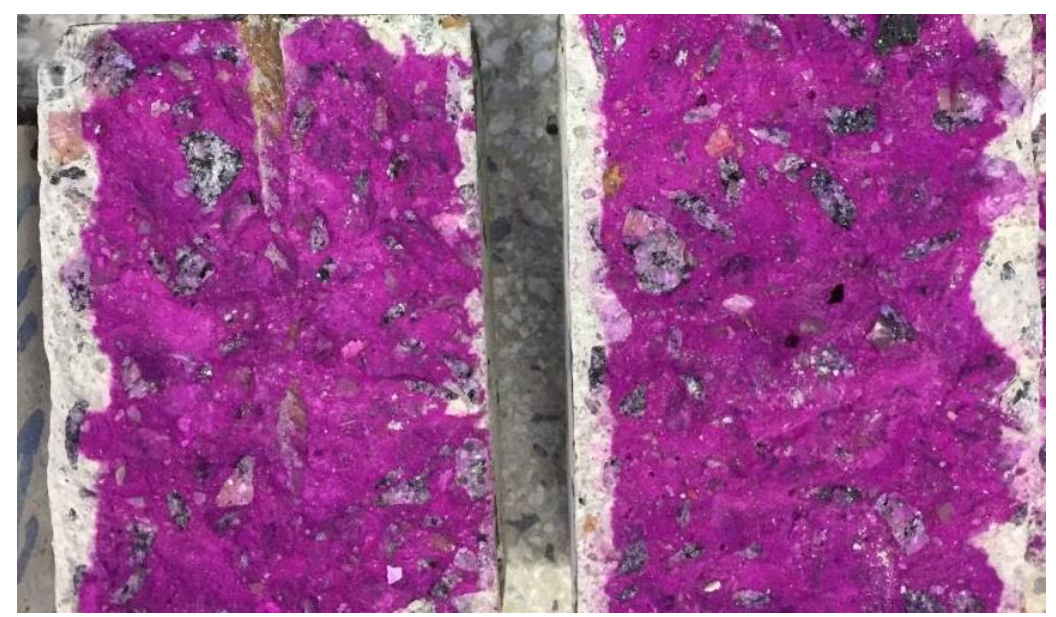

Fonte: Autores, (2021).

Após a aspersão da fenolftaleína foi feita a medição da profundidade de carbonatação dos corpos de prova. A profundidade de carbonatação para todas as famílias se obteve através da (Equação 1).

$\mathrm{X}=(\mathrm{C} 1+\mathrm{C} 2+\mathrm{C} 3) / 3$

Onde: X é a profundidade média da carbonatação; C1 é dado pelo somatório de todas as profundidades de carbonatação do lado direito do $\mathrm{CP}$; $\mathrm{C} 2$ é definido pelo somatório de todas as profundidades de carbonatação do lado esquerdo do C; C3 é caracterizado pelo somatório de todas as profundidades de carbonatação do fundo do CP.

Ao substituir os resultados obtidos na equação, obteve-se os seguintes resultados: para a família dos (CP's) de referência, houve uma profundidade de carbonatação de 4,3 mm; para a família de dos (CP's) de 15\% de RCC, houve uma profundidade de 6,2 mm; para os (CP's) de 25\% de RCC, obteve-se uma profundidade de 7,8 $\mathrm{mm}$ e, por fim, para os (CP's) de 50\% obteve-se uma profundidade correspondente de $9 \mathrm{~mm}$. Pode-se perceber que a carbonatação não chegou às barras de aço, sabendo que o cobrimento das barras de aço é de $2,0 \mathrm{~cm}$ e que o maior valor encontrado foi menor que $1 \mathrm{~cm}$ para os corpos de prova com $50 \%$ de RCC.

Estes resultados indicam que o ensaio de potencial de corrosão está correto, uma vez que com exceção do traço com 50\% de agregado reciclado, se manteve na zona de incerteza e ao fazer as leituras da profundidade, ficou evidente que em nenhum corpo de prova submetido à carbonatação acelerada atingiu as barras, desencadeando a corrosão das mesmas. Assim, concretos feitos com agregados reciclados podem apresentar 
profundidade de carbonatação 2,5 vezes maior que os concretos convencionais e ainda segundo o autor, concretos feitos com $100 \%$ de RCC esta diferença pode ser de 8,7 vezes devido a porosidade do material (ZHAO et al., 2020; LOLLINI; RADAELLI, 2021).

\section{Projeção do tempo de vida útil}

A determinação da vida útil de elementos estruturais sob o processo de corrosão, foi analisado através do programa de linguagem Fortran baseando-se no MEF - Método dos Elementos Finitos descrito por Coda (2003). Para determinar o tempo de vida útil, utilizou-se uma adaptação realizada pelos pesquisadores Félix, Carrazebo e Possan (2017), onde foi possível observar a propagação do processo de corrosão frente a ação da carbonatação. Esse processo pode comprometer a durabilidade das estruturas, pois afeta diretamente as barras de aço de forma generalizada. Segundo Vu e Stewaert (2000), se é possível determinar a taxa de corrosão das armaduras (Equação 2) e, sobretudo, o diâmetro integro da barra de aço (Equação 3) utilizado na composição concreto armado.

$$
\begin{aligned}
& \eta=\left(\frac{37,8 *\left(1-\left(\frac{a}{c}\right)\right)^{-1,64}}{c o b}\right) * 0,85 *\left(t_{p}\right)^{-0,29} \\
& d\left(t_{p}\right)=d_{0}-\left(2 * 0,00116 * \eta * t_{p}\right)
\end{aligned}
$$

Onde: $\mathrm{d}\left(t_{p}\right)$ é o diâmetro integro de aço (em $\mathrm{mm}$ ) no tempo $t_{p}$ (em anos) após iniciar o período de progressão da corrosão; $d_{0}$ é o diâmetro inicial da barra $(\mathrm{mm}), \eta$ representa a taxa de corrosão da armadura $\left(\mu \mathrm{A} / \mathrm{cm}^{2}\right) ;(\mathrm{a} / \mathrm{c})$ é a relação água/cimento do concreto; $c o b$ é a espessura do concreto de cobrimento (mm). Para a determinação do instante inicial da despassivação das barras de aço, foi utilizado um modelo frente a profundidade de carbonatação do concreto interpretado pela aplicação das RNA's - Redes Neurais Artificiais, conforme aplicado por Félix (2016).

As variáveis do modelo e o tipo de rede responsável por descrever esse fenômeno podem ser vistas na (Figura 14). Para a validação do modelo observou-se que teor de $\left(\mathrm{CO}_{2}\right)$ foi de $0,7 \%$, a umidade relativa era de $95 \%$, o tipo de cimento utilizado foi o CP II Z-32, o cobrimento nominal foi de $2,5 \mathrm{~mm}$, a relação $(\mathrm{a} / \mathrm{c})$ foi de 0,55 e a resistência média a compressão axial foi de $28 \mathrm{MPa}$. 
Figura 14 - Variáveis do modelo proposto e topologia da RNA.

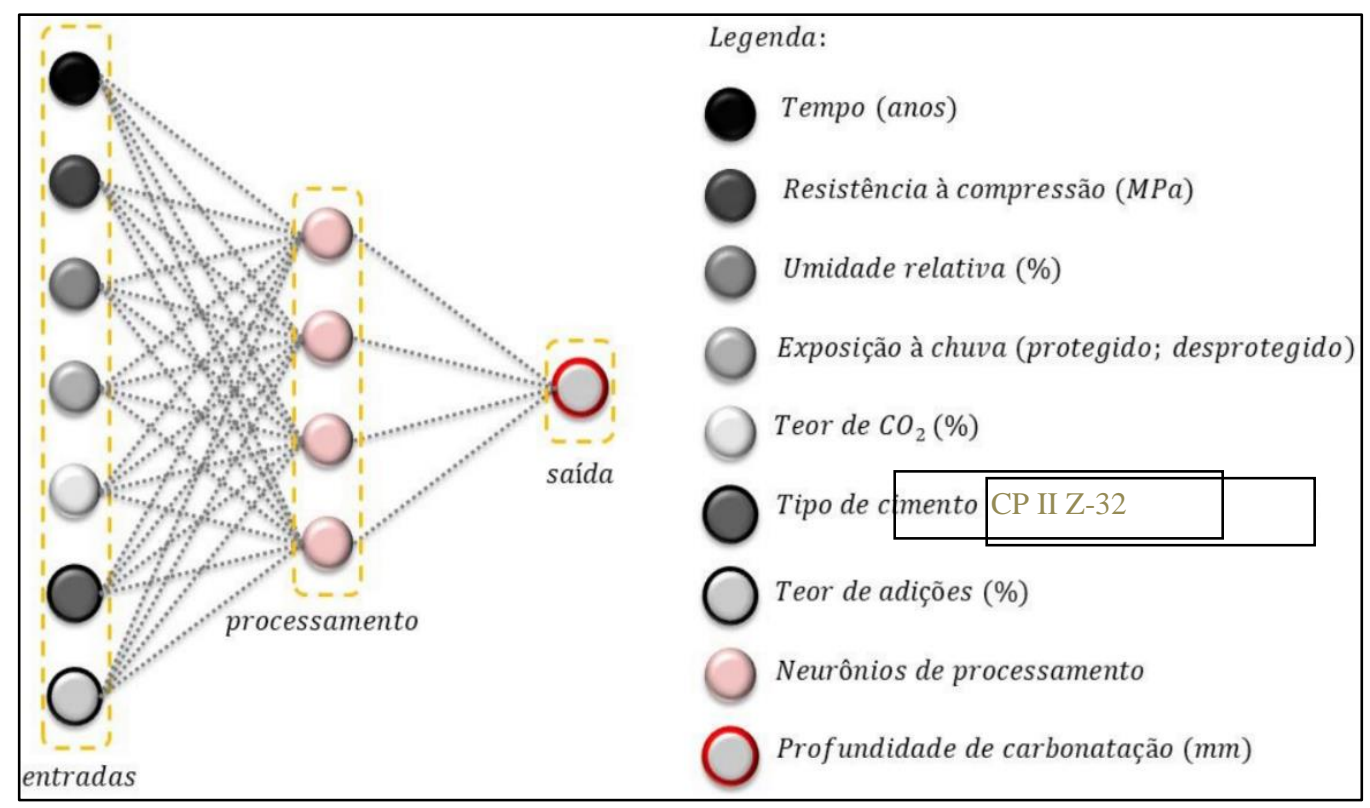

Fonte: Félix, Carrazebo e Possan, (2017).

O processo de difusão acelerada de dióxido de carbono confere as armaduras um aumento da profundidade de carbonatação e, sobretudo, o aumento da taxa de corrosão. Sabe-se, portanto, que a frente de $\left(\mathrm{CO}_{2}\right)$ incidida aos corpos-de-prova foi controlada, ou seja, a umidade relativa manteve-se fixa. Na (Figura 15), percebe-se que o aumento da degradação das barras de aço ocorre com o tempo de exposição, mas todos os traços se mantiveram com o mesmo comportamento nos primeiros dias.

Os corpos-de-prova de referência obtiveram os melhores resultados quando comparados com os outros traços tendo, portanto, valores exponenciais mais significativos sendo o valor do $\mathrm{R}^{2}$ mais próximo de 1,0. Assim, observa-se que em 5 anos os valores percentuais da profundidade de carbonatação, comparado com os traços de $15 \%, 25 \%$ e $50 \%$ de (RCC) foram de $31 \%, 45 \%$ e $52 \%$, respectivamente. 
Figura 15 - Avanço da profundidade de carbonatação.

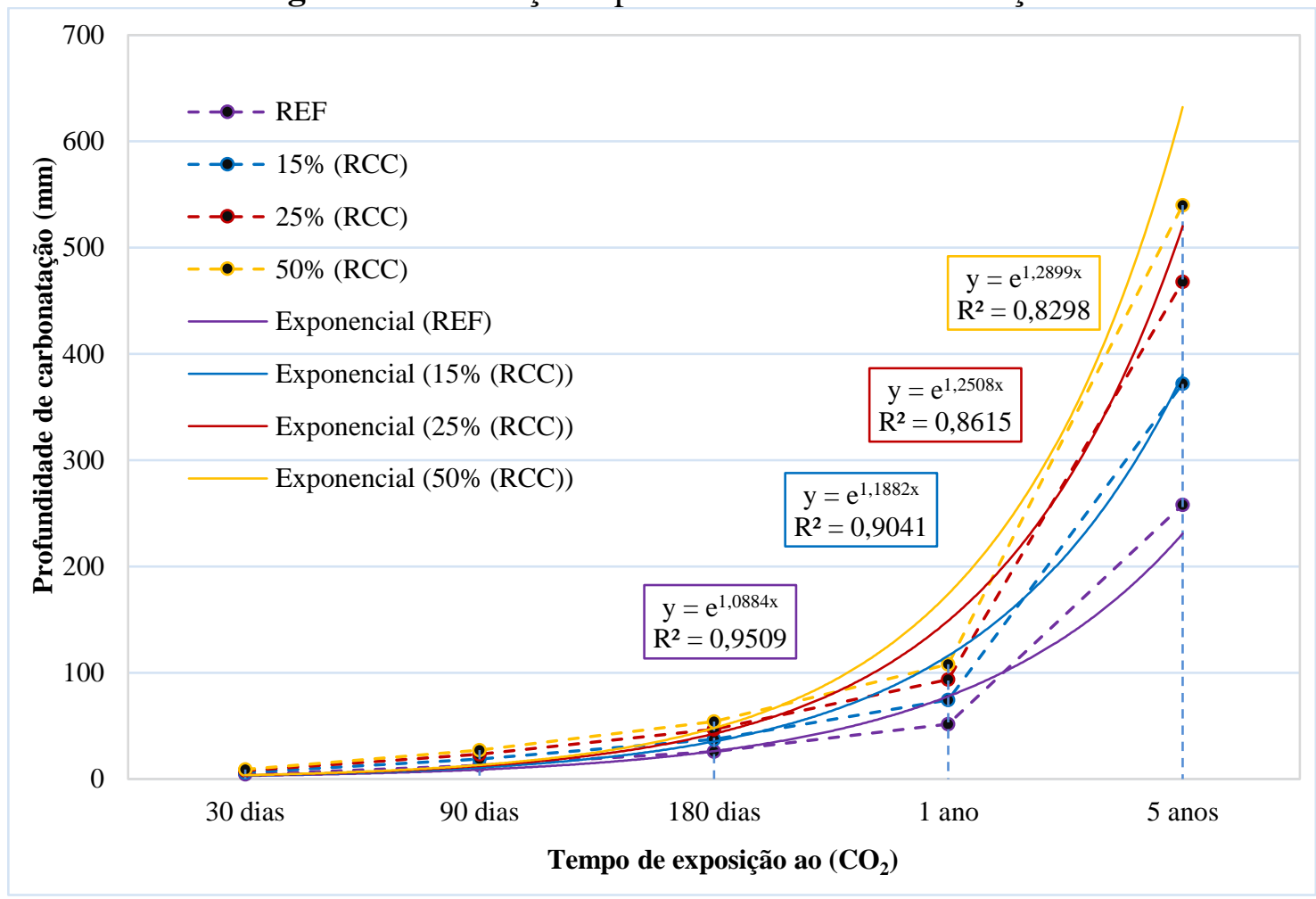

Fonte: Autores, (2021).

O processo de difusão acelerada de dióxido de carbono confere as armaduras um aumento da profundidade de carbonatação e, sobretudo, o aumento da taxa de corrosão. Sabe-se, portanto, que a frente de $\left(\mathrm{CO}_{2}\right)$ incidida aos corpos-de-prova foi controlada, ou seja, a umidade relativa manteve-se fixa. Na (Figura 15), percebe-se que o aumento da degradação das barras de aço ocorre com o tempo de exposição, mas todos os traços se mantiveram com o mesmo comportamento nos primeiros dias.

Os corpos-de-prova de referência obtiveram os melhores resultados quando comparados com os outros traços tendo, portanto, valores exponenciais mais significativos sendo o valor do $\mathrm{R}^{2}$ mais próximo de 1,0. Assim, observa-se que em 5 anos os valores percentuais da profundidade de carbonatação, comparado com os traços de $15 \%, 25 \%$ e $50 \%$ de (RCC) foram de $31 \%, 45 \%$ e $52 \%$, respectivamente.

Segundo Ghorbani et al., (2019), Ogork e Ibrahim (2016), a utilização de maiores percentuais de (RCC) pode comprometer a fluidez ótima do composto cimentício, ou seja, a trabalhabilidade é afetada e pode ocasionar dispersão dos materiais finos na microestrutura. Essa dispersão condiciona o aumento de vazios devido a segregação dos materiais e, sobretudo, facilita o ingresso de agentes agressivos através do deslocamento da água. 
A corrosão não afetou as barras de aço em nenhum dos traços, porém ao avaliar o comportamento do material durante a projeção de 5 anos (Figura 16), percebe-se que houve um aumento de 70\% para os (CP's) de referência, porém ao analisar os (CP's) com $15 \%$ e $25 \%$ de (RCC), os mesmos tiveram comportamentos semelhantes. Quanto aos (CP's) com 50\% de (RCC), o aumento da taxa de corrosão variou entre $65 \%$ e $70 \%$ devido as características físicas do material quanto ao índice de vazios.

A perda de massa não foi avaliada nessa pesquisa, mas ao estudar a diminuição do diâmetro íntegro das barras, percebeu-se que em 5 anos a mesma diminuiu em aproximadamente $15 \%$ para todos os traços sendo o valor nominal de 5,50 mm. Segundo Amorim Júnior et al., (2019) e Oliveira et al., (2020), o aumento da taxa de corrosão das barras de aço frente a projeção do tempo de exposição a difusão de dióxido de carbono é diretamente proporcional, uma vez que a carbonatação integra e degrada toda a camada passivadora do aço provocando a perda de seção generalizada diminuindo o tempo de vida útil da estrutura.

Figura 16 - Comportamento físico das barras de aço frente a presença de $\mathrm{CO}_{2}$.

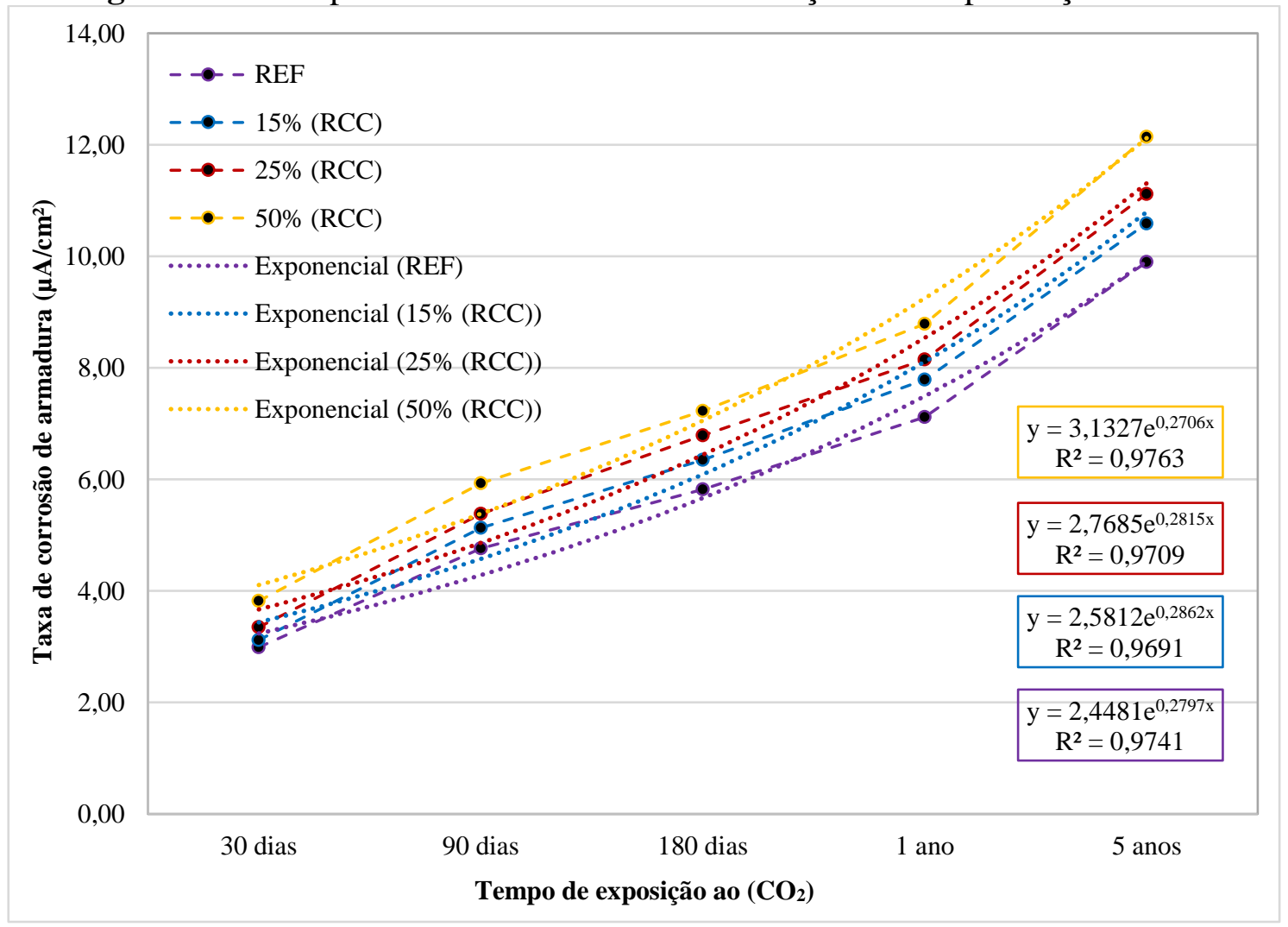

Fonte: Autores, (2021). 


\section{CONSIDERAÇÕES FINAIS}

Em tese, é necessário entender a finalidade de construirmos obras com uma boa durabilidade frente ao ataque de agentes agressivos como o dióxido de carbono $\left(\mathrm{CO}_{2}\right)$. Assim, nesse artigo foram destacados alguns pontos:

- O agregado reciclado utilizado nesta pesquisa apresentou teor de materiais finos, ou seja, pulverulentos, $50 \%$ superior ao agregado miúdo natural, o que pode ter inferido na consistência e absorção de água dos concretos;

- Conclui-se que a câmara de carbonatação acelerada, utilizada para potencializar a corrosão generalizada das armaduras usados no concreto em estudo foi eficiente;

- Acredita-se que o concreto com $15 \%$ e $25 \%$ seriam os mais adequados no âmbito da sustentabilidade e, sobretudo, para mitigar a difusão de $\left(\mathrm{CO}_{2}\right)$ no concreto;

- O concreto com o traço de $50 \%$ por ter apresentado resultado maior, este seria o menos indicado a exposição ao $\left(\mathrm{CO}_{2}\right)$ por ser um material com um grande índice de vazios;

- A profundidade de carbonatação é diretamente proporcional a taxa de corrosão das barras de aço e, sobretudo, diminui o diâmetro nominal da armadura exponencialmente ao decorrer do tempo;

- Todos as misturas tiveram um bom comportamento quanto a taxa de corrosão, mas os corpos-de-prova com 50\% de (RCC) tiveram uma maior profundidade de carbonatação;

- Os corpos-de-prova com $15 \%$ e $25 \%$ de (RCC) se comportaram semelhantemente aos (CP's) de referência quando analisados a taxa de corrosão de armadura. Os mesmos tiveram valores que variaram entre $65 \%$ e $70 \%$ e todos os resultados são estatisticamente parecidos, pois o $\mathrm{R}^{2}$ varia entre 0,96 e 0,97 ;

- Os agregados reciclados influenciaram diretamente na homogeneidade da pasta do concreto levando em consideração a relação água/cimento e o índice de vazios podendo ser comprovado através do ensaio de aspersão de fenolftaleína;

Portanto, para conhecer e aprofundar ainda mais sobre o tema, outras análises deverão ser feitas posteriormente para compreender o comportamento mineralógico do material e quais são as influências, quimicamente, que esse material tem no concreto. 


\section{REFERÊNCIAS BIBLIOGRÁFICAS}

ABNT - ASSOCIAÇÃO BRASILEIRA DE NORMAS TÉCNICAS. NBR NM 45: Agregado em estado solto - determinação da massa unitária. Rio de Janeiro, 2006.

ABNT - ASSOCIAÇÃO BRASILEIRA DE NORMAS TÉCNICAS. NBR NM 53: Agregado graúdo - Determinação de massa específica, massa específica aparente e absorção de água. Rio de Janeiro, 2009.

ABNT - ASSOCIAÇÃO BRASILEIRA DE NORMAS TÉCNICAS. NBR NM 67: Concreto - Determinação da consistência pelo abatimento do tronco de cone. Rio de Janeiro, 1998.

ABNT - ASSOCIAÇÃO BRASILEIRA DE NORMAS TÉCNICAS. NBR NM 248: Agregados - Determinação da composição granulométrica. Rio de Janeiro, 2003.

ABNT - ASSOCIAÇÃO BRASILEIRA DE NORMAS TÉCNICAS. NBR 6118: Projeto de estruturas de concreto - procedimento. Rio de Janeiro, 2014.

ABNT - ASSOCIAÇÃO BRASILEIRA DE NORMAS TÉCNICAS. NBR 7211: Agregado para concreto - Especificação. Rio de Janeiro, 2005.

ABNT. ASSOCIAÇÃO BRASILEIRA DE NORMAS TÉCNICAS. NBR 15116: Agregados reciclados de resíduos sólidos da construção civil - Utilização em pavimentação e preparo de concreto sem função estrutural - Requisitos. Rio de Janeiro, 2004.

ABNT - ASSOCIAÇÃO BRASILEIRA DE NORMAS TÉCNICAS. NBR 15575: Edificações Habitacionais - Desempenho Parte 1: Requisitos Gerais - Referências Elaboração. Rio de Janeiro, 2013.

ANDRADE, J. J. O.; POSSAN, E.; DAL MOLIN, D. C. C. Considerations about the service life prediction of reinforced concrete structures inserted in chloride environments. Journal of Building Pathology and Rehabilitation, [S.L.], v. 2, n. 1, p. 1-8, 29 jun. 2017. Springer Science and Business Media LLC. http://dx.doi.org/10.1007/s41024-0170025-x. 
ASTM International - ASTM G1 - 03. Standard Practice for Preparing, Cleaning, and Evaluating Corrosion Test Specimens. West Conshohocken, PA, 2017. DOI: 10.1520/G0001-03R17E01

ASTM International - C 876. Standard test method for halh cell potential of uncoated reinforcing steel in concrete, Annual Book of ASTM Standards, Philadelphia, 2015.

AZEVEDO, A. R. G.; MARVILA, M. T.; ROCHA, H. A.; CRUZ, L. R.; VIEIRA, C. M. F. Use of glass polishing waste in the development of ecological ceramic roof tiles by the geopolymerization process. International Journal of Applied Ceramic Technology, [S.L.], v. 17, n. $6, \quad$ p. 2649-2658, 16 jul. 2020. Wiley. http://dx.doi.org/10.1111/ijac.13585.

AMORIM JÚNIOR, N. S.; SILVA, G. A O.; DIAS, C. M. R.; RIBEIRO, D. V. Concrete containing recycled aggregates: estimated lifetime using chloride migration test. Construction and Building Materials, [S.L.], v. 222, p. 108-118, out. 2019. Elsevier BV. http://dx.doi.org/10.1016/j.conbuildmat.2019.06.136.

BARRETO, E. S.; STAFANATO, K. V.; MARVILA, M. T.; AZEVEDO, A. R. G.; ALI, M.; PEREIRA, R. M. L.; MONTEIRO, S. N. Clay Ceramic Waste as Pozzolan Constituent in Cement for Structural Concrete. Materials, [S.L.], v. 14, n. 11, p. 2917, 28 maio 2021. MDPI AG. http://dx.doi.org/10.3390/ma14112917.

BRASIL. Ministério do Meio Ambiente. Resolução CONAMA n. 307, de 5 de julho de 2002, estabelece diretrizes, critérios e procedimentos para a gestão de resíduos da construção civil, 2002. Diário Oficial da União, n. 136, de 17 de julho de 2002, Seção 1, p. 95-96.

CODA, H. B. Análise não linear geométrica de sólidos e estruturas: uma formulação posicional baseada no MEF. Volume II, Departamento de Estruturas, Escola de Engenharia de São Carlos, Universidade de São Paulo, São Carlos, 2003.

COSTA, F. N.; RIBEIRO, D. V. Reduction in $\left(\mathrm{CO}_{2}\right)$ emissions during production of cement, with partial replacement of traditional raw materials by civil construction waste (CCW). Journal of Cleaner Production, [S.L.], v. 276, p. 123302, dez. 2020. Elsevier BV. http://dx.doi.org/10.1016/j.jclepro.2020.123302. 
ELLINGWOOD, B. R.; FRANGOPOL, D. M. Introduction to the state-of-the-art collection: risk - based lifecycle performance of structural systems. Journal of Structural Engineering. V.142, pp. 1, 2016.

FÉLIX, E. F. Desenvolvimento de software para a estimativa da profundidade de carbonatação, vida útil e captura de $\left(\mathrm{CO}_{2}\right)$ de estruturas de concreto empregando RNA's. Trabalho de conclusão de curso, Universidade Federal da Integração LatinoAmericana, Foz do Iguaçu, 2016.

FÉLIX, E. F.; CARRAZEDO, R.; POSSAN, E. Análise Paramétrica da carbonatação em estruturas de concreto armado via Redes Neurais Artificiais. Revista Alconpat, v. 7, n. 3, p. 302-316, 2017.

FÉLIX, E. F.; BALABUCH, T. J. R.; POSTERLLI, M. C.; POSSAN, E.; CARRAZEDO, R. Análise da vida útil de estruturas de concreto armado sob corrosão uniforme por meio de um modelo com RNA acoplado ao MEF. Revista Alconpat, [S.L.], v. 8, n. 1, p. 1-15, 31 jan. 2018. Revista ALCONPAT. http://dx.doi.org/10.21041/ra.v8i1.256.

GHORBANI, S.; SHARIFI, S.; GHORBANI, S.; TAM, V. W.; BRITO, J.; KURDA, R. Effect of crushed concrete waste's maximum size as partial replacement of natural coarse aggregate on the mechanical and durability properties of concrete. Resources, Conservation and Recycling, [S.L.], v. 149, p. 664-673, out. 2019. Elsevier BV. http://dx.doi.org/10.1016/j.resconrec.2019.06.030.

KHAN, M. U.; AHMAD, S.; AL-GAHTANI, H. J. Chloride-Induced Corrosion of Steel in Concrete: an overview on chloride diffusion and prediction of corrosion initiation time. International Journal of Corrosion, [S.L.], v. 2017, p. 1-9, 2017. Hindawi Limited. http://dx.doi.org/10.1155/2017/5819202.

KÖLIÖ, A.; PAKKALA, T. A.; HOHTI, H.; LAUKKARINEN, A.; LAHDENSIVU, J.; MATTILA, J.; PENTTI, M. The corrosion rate in reinforced concrete facades exposed to outdoor environment. Materials and Structures, [S.L.], v. 50, n. 1, p. 1-16, 10 ago. 2016. Springer Science and Business Media LLC. http://dx.doi.org/10.1617/s11527-016-09207. 
LOLLINI, F.; REDAELLI, E. Corrosion rate of carbon steel in carbonated concrete made with different supplementary cementitious materials. Corrosion Engineering, Science and Technology, [S.L.], v. 56, n. 5, p. 473-482, 22 abr. 2021. Informa UK Limited. http://dx.doi.org/10.1080/1478422x.2021.1916236.

MACDONALD, D. D.; QIU, J.; ZHU, Y.; YANG, J; ENGELHARDT, G. R.; SAGÜÉS, A. Corrosion of rebar in concrete. Part I: calculation of the corrosion potential in the passive state. Corrosion Science, [S.L.], v. 177, p. 109018, dez. 2020. Elsevier BV. http://dx.doi.org/10.1016/j.corsci.2020.109018.

MANFRINATO, J. W. S.; ESGUÍCERO, F. J.; MARTIS, B. L. Implementação de Usina Para Reciclagem de Resíduos da Construção Civil (RCC) como ação para o Desenvolvimento Sustentável: estudo de caso. In: Encontro Nacional de Engenharia De Produção, 28. Rio de Janeiro, 2008. Anais... Rio de Janeiro, 2008.

MARQUES, P. H. R. J. Análise sa Influência de Espaçadores na Corrosão de Armaduras em Concretos Induzidos por Carbonatação. 105 f. Dissertação (Mestrado) - Curso de Engenharia Civil, Departamento de Construção Civil, Universidade Católica de Pernambuco, Recife, 2018.

MARTÍNEZ-MOLINA, W.; TORRES-ACOSTA, A. A.; ALONSO-GUZMÁN, E. M.; CHÁVEZGARCÍA, H. L.; HERNÁNDEZ-BARRIOS, H.; LARA-GÓMEZ， C.; MARTÍNEZ-ALONSO, E. M.; PÉREZ-QUIROZ, J. T.; BEDOLLA-ARROYO, J. A.; GONZÁleZ-VALDÉZ, F. M. Concreto reciclado: una revisión. Revista Alconpat, Volume 5, Número 3, Septembro - dezembro 2015, Páginas 234 - 247. México, 2016.

MONTEIRO, E. C. B. Avaliação do método de extração eletroquímica de cloretos para reabilitação de estruturas de concreto com problemas de corrosão de armaduras. 229 f. Tese (Doutorado) - Curso de Engenharia Civil, Universidade de São Paulo, São Paulo, 2002.

MORLA, P.; GUPTA, R.; AZARSA, P.; SHARMA, A. Corrosion Evaluation of Geopolymer Concrete Made with Fly Ash and Bottom Ash. Sustainability, [S.L.], v. 13, n. 1, p. 398, 4 jan. 2021. MDPI AG. http://dx.doi.org/10.3390/su13010398. 
NAIK, G. M.; NARENDRANATH, S.; KUMAR, S. S. Satheesh. The Role of Processing Temperature in Equal Channel Angular Extrusion: microstructure mechanical properties and corrosion resistance. Lecture Notes in Mechanical Engineering, [S.L.], p. 277-285, 2020. Springer Singapore. http://dx.doi.org/10.1007/978-981-15-3631-1_25.

NUNES, D. G. Carbonatação acelerada em concretos compostos com cinza de casca de arroz de diferentes teores de carbono grafítico, Dissertação (Mestrado) Universidade Federal de Santa Maria, 2014.

OGORK, E.; IBRAHIM, T. Properties of Cement Paste and Concrete Containing Calcium Carbide Waste as Additive. Nigerian Journal of Technology, [S.L.], v. 36, n. 1, p. 26-31, 28 dez. 2016. African Journals Online (AJOL). http://dx.doi.org/10.4314/njt.v36i1.4.

OLIVEIRA, J. P.; SANTOS, C. H.; OKUMURA, M. L.; YAMAGUCHI, N. U. Concrete performance evaluation of coarse aggregate replacement by civil construction waste. Revista Eletrônica em Gestão, Educação e Tecnologia Ambiental, [S.L.], v. 24, p. 52-63, 7 jul. 2020. Universidad Federal de Santa Maria. http://dx.doi.org/10.5902/2236117043603.

Performance standards in building - Principles for their preparation and factors to be considered. ISO 6241. 1984.

POSSAN, E. Modelagem da carbonatação e previsão de vida útil de estruturas de concreto em meio urbano. Tese de Doutorado em Engenharia, Programa de PósGraduação em Engenharia Civil, Universidade Federal do Rio Grande do Sul, Porto Alegre, 2010.

SAMSON, G.; DEBY, F.; GARCIAZ, J-L.; LASSOUED, M. An alternative method to measure corrosion rate of reinforced concrete structures. Cement and Concrete Composites, [S.L.], v. 112, p. 103672, set. 2020. Elsevier BV. http://dx.doi.org/10.1016/j.cemconcomp.2020.103672.

SOHAIL, M. G.; LAURENS, S.; DEBY, F.; BALAYSSAC, J. P.; NUAIMI, N. A. Electrochemical corrosion parameters for active and passive reinforcing steel in carbonated and sound concrete. Materials and Corrosion, [S.L.], 26 jul. 2021. Wiley. http://dx.doi.org/10.1002/maco.202112569. 
SOUSA, C.; SOUZA, N. L.; ROSSE, V.; SILVEIRA, P. H.; BARBOSA, M. T. Utilisation of dairy waste as a release agent and plastisizer for civil construction. International Journal of Sustainable Engineering, [S.L.], p. 1-8, 18 ago. 2021. Informa UK Limited. http://dx.doi.org/10.1080/19397038.2021.1966124.

TRAN, D. V. P.; SANCHAROEN, P.; KLOMJIT, P.; TANGTERMSIRIKUL, S. Electrical resistivity and corrosion potential of reinforced concrete: influencing factors and prediction models. Journal of Adhesion Science and Technology, [S.L.], v. 34, n. 19, p. 2107-2119, 29 abr. 2020. Informa UK Limited. http://dx.doi.org/10.1080/01694243.2020.1750784.

VIEIRA, D. V.; PELISSER, F.; SILVA, P. M. M.; MOHAMAD, G.; NÓBREGA, A. C. V. Estudo de inibidores de corrosão em concreto armado. Revista Matéria, v. 15, n. 3, p. 431-444, 2010. FapUNIFESP (SciELO). http://dx.doi.org/10.1590/s151770762010000300006 .

VU, K. A. T.; STEWART, M. G. Structural reliability of concrete bridges including improved chloride-induced corrosion models. Structural Safety, v. 22, p. 313-333, 2000.

ZHAO, K.; LIANG, Y.; JI, T.; LU, Y.; LIN, X. Effect of activator types and concentration of $\left(\mathrm{CO}_{2}\right)$ on the steel corrosion in the carbonated alkali-activated slag concrete. Construction and Building Materials, [S.L.], v. 262, p. 120044, nov. 2020. Elsevier BV. http://dx.doi.org/10.1016/j.conbuildmat.2020.120044.

ZORDAN, S. E. A utilização do entulho como agregado na confecção do concreto. 1997. Dissertação (Mestrado) - Departamento de Saneamento e Meio Ambiente da Faculdade de Engenharia Civil, Universidade Estadual de Campinas, Campinas - SP. 1997.

Recebido em: 01/10/2021

Aprovado em: 25/10/2021

Publicado em: 28/10/2021 